\title{
Large Hybrid Polymer/Lipid Unilamellar Vesicle (LHUV) at the nanoscale: An insight into the lipid distribution in the membrane and permeability control
}

\author{
Martin Fauquignon ${ }^{1}$, Elise Courtecuisse ${ }^{1}$, Romane Josselin ${ }^{1}$, Angela Mutschler ${ }^{1}$ Annie Brûlet ${ }^{2}$, Marc \\ Schmutz ${ }^{3}$ and Jean-François Le Meins ${ }^{1, \star}$ \\ 1 Université de Bordeaux, CNRS, Bordeaux INP, LCPO, UMR 5629, F-33600, Pessac, France \\ 2 Université Paris-Saclay, Laboratoire Léon Brillouin, UMR12 CEA-CNRS, CEA Saclay, F-91191 Gif-sur-Yvette \\ Cedex, France \\ 3 Université de Strasbourg, CNRS, ICS, UPR 22, 23 rue du Loess, F-67000 Strasbourg, France
}

Martin Fauquignon: Martin.Fauquignon@enscbp.fr

Elise Courtecuisse: Elise.Courtecuisse@enscbp.fr

Romane Josselin: Romane.Josselin@enscbp.fr

Annie Brûlet: annie.brulet@cea.fr

Marc Schmutz: marc.schmutz@ics-cnrs.unistra.fr

Angela Mutschler: angela.mutschler@enscbp.fr

Corresponding author:

lemeins@enscbp.fr

tel: +33(0)5-5684-6194

Membrane structuration of Large Hybrid Unilamellar Polymer/Lipid Vesicle (LHUV) is an important parameter on the optimization of their properties and thus their valuation in various fields. However, this kind of information is hardly accessible. In this work, we will focus on the development of LHUV obtained from the self-assembly of diblock poly(dimethylsiloxane)- $b$ poly(ethylene oxide) (PDMS- $b$-PEO) of different molar masses combined with 1-palmitoyl-2oleoyl-sn-glycero-3-phosphocholine (POPC) at $15 \%$ and $25 \% \mathrm{w} / \mathrm{w}$ content. The hybrid character of the resulting vesicles as well as their membrane structure are characterized by the mean of different techniques such as small-angle neutron scattering (SANS) and cryotransmission electron microscopy (cryo-TEM). We show that hybrid vesicles with homogeneous membrane structure are obtained whatever the molar mass of the block copolymer (from 2500 to $4000 \mathrm{~g} / \mathrm{mol}$ ), with of a small number of tubular structures observed with the higher molar mass. We also demonstrate that the permeability of the LHUV, evaluated through controlled release experiments of fluorescein loaded in LHUV, is essentially controlled by the lipid/polymer composition.

\section{Keywords:}

Hybrid Polymer/Lipid Vesicle

Membrane permeability

Polymersomes

Liposomes

Small Angle Neutron Scattering (SANS)

Cryo Transmission Electron Microscopy (Cryo-TEM)

Nanoreactor 


\section{Introduction}

Synthetic vesicles are the subject of an increasing number of studies because of their interest in numerous applications fields. Among them, drug targeting and delivery, biosensor and nanoreactor development (artificial organelle) are particularly considered. Liposomes obtained from the self-assembly of phospholipids have been thoroughly investigated since their discovery in the sixties, because of their biocompatible and biofunctional character. As a drug delivery system, it has been evidenced that liposomes could provide improved therapeutic efficacy and reduced systemic toxicity. But, even though some drug delivery systems based on liposomal suspensions have been approved by the health authorities (Myocet@, Daunoxome ${ }^{\circledR}$, Doxil $\left({ }^{\circledR}\right.$, Onivyde $\left.{ }^{\mathrm{TM}} \ldots\right)$, their use is yet relatively limited despite years of research due to their inherent membrane fragility and high membrane permeability. In the last few decades, polymersomes obtained by self-assembly of block copolymers appeared as kind of analogue of liposomes but with higher functional viability and robustness. ${ }^{1-4}$ More recently, hybrid polymer/lipid vesicles appeared to be a promising alternative of their forerunners as they could combine synergistically the advantages of each component. ${ }^{5-7}$

So far, many studies have sought to highlight the interest of these hybrid polymer/lipid vesicles for different pharmaceutical, biological or biochemical applications like nano bioreactor, ${ }^{8-15}$ drug delivery and targeting system, ${ }^{16-22}$ or molecular recognition. ${ }^{23}$ A relatively few number of studies have focused on the self-assembly, membrane structure and properties relationship of these hybrid systems. ${ }^{24,25-27}$

Evidences of the hybrid nature of these vesicles at nanoscale are rare, and the membrane structure most often remains unknown. Dynamic Light Scattering (DLS), Differential Scanning Calorimetry and Cryogenic Transmission Electron Microscopy (Cryo-TEM) were used to evaluate the hybrid character of LHUV. ${ }^{19,20,24}$ Dual-color Fluorescence Cross-Correlation Spectroscopy was also used to prove efficiently hybrid character of Large Hybrid Unilamellar vesicles ${ }^{28}$ but information about the membrane morphology are almost inexistent. Recent studies of our group have shown that LHUV presenting lipid domains could be obtained..$^{29,30}$ Generally, there is a lack of information about the molecular and process parameters leading to LHUV presenting a homogeneous mixture of components or, in contrast, a lateral phase separation in the membrane. This is mainly due to a lack of systematic approach in literature where polymers used could present different chemical composition, molar mass or architecture from a study to another. It is however important, in order to perfectly exploit the potential of such systems, to increases our knowledge about the relationship between molecular parameters of the constituting blocks of LHUV and their membrane structuration and properties. As these systems are highly regarded for applications such as controlled drug delivery or development of nanoreactors, it is essential to control and rationalize their membrane permeability.

For now, different systems have been analyzed and it has been shown that LHUV composed of poly(butadiene)- $b$-poly(ethylene oxide) $\left(\mathrm{PBD}_{22}-b-\mathrm{PEO}_{14}\right)$ and 1-palmitoyl-2-oleoyl-snglycero-3-phosphocholine (POPC) at a molar fraction of $50 \%$ show permeability to calcein acetomethoxylester between those of pure liposomes and polymersomes. ${ }^{31}$ Similar observations have already been made on the same system at different lipid molar fraction (25, 50 and $75 \%$ ) during carboxyfluorescein release experiments. ${ }^{19}$ In hybrid vesicle obtained from poly(lactic acid)-b-poly(ethylene oxide) (PLA $\left.{ }_{54}-b-P^{-} O_{45}\right)$, and POPC, the presence of copolymer tends to decrease the release kinetic of carboxyfluorescein compared to pure POPC vesicles. This effect increases with the molar content of the copolymer. ${ }^{16}$ All these results correspond to what is « expected » for such mixture. However, it is interesting to note that in other studies it has been reported that the permeability of hybrid membrane towards $\mathrm{H}^{+} / \mathrm{OH}$ seems to be different, as LHUVs composed of $\mathrm{PBD}_{37}-b-\mathrm{PEO}_{22}$ and $\mathrm{DOPC}$, tend to be 
even more permeable than pure liposomes. ${ }^{13}$ Experiments have been performed also on hybrid films based on dipalmitoylphosphatidylcholine (DPPC) and PBD- $b$-PEO: the release of hydrophobic drug, Paclitaxel, has been shown to be faster with hybrid films than with pure components films. ${ }^{32}$ Globally, it is difficult to extract general tendencies from these results, as physicochemical properties of the molecules considered, are very different from one study to another. Moreover, the membrane structure of the hybrid system considered is most often unknown.

In this work, we pursue a systematic investigation that consists in extracting molecular parameters that modulate the membrane structure of hybrid polymer/lipid vesicles. In previous studies, we have demonstrated that the association of poly(ethylene oxide)- $b$ poly(dimethylsiloxane)- $b$-poly(ethylene oxide) (PEO- $b$-PDMS- $b$-PEO) triblock copolymer associated with DPPC in gel or fluid state led to the formation of LHUV that could present lipid nanodomains. This was evidenced by SANS, cryo-TEM and time-resolved FRET. ${ }^{29}$ Here, we present a complete study of the association of PDMS- $b$-PEO diblock copolymer and a phospholipid (POPC) in a fluid state into LHUV. Their hybrid character and the membrane structure have been studied by DLS, SANS and cryo-TEM. Membrane thicknesses of the polymersomes obtained from those diblock copolymers were similar to those obtained with triblock. Therefore, with such an approach, we hope to decipher the effect of the copolymer architecture on the membrane structure of the corresponding LHUV. In addition, we have evaluated through fluorescein release experiments the influence of lipid content and copolymer molar mass on the membrane permeability.

\section{Materials}

POPC (1-palmitoyl-2-oleoyl-sn-glycero-3-phosphocholine), partially deuterated POPC-d31 (1palmitoyl-d31-2-oleoyl-sn-glycero-3-phosphocholine) and DOPE-Rhod (1,2-dioleoyl-snglycero-3-phosphoethanolamine-N-(lissamine rhodamine B sulfonyl)) were obtained from Avanti Polar Lipids Inc (Alabaster, AL, Canada). Fluorescein was purchased from Aldrich.

The different diblock copolymers PDMS- $b$-PEO and the NBD-labelled PDMS were synthesized and characterized according to protocol described in a previous study ${ }^{33}$. The molecular characteristics are summarized in Table 1.

\begin{tabular}{|c|c|c|c|c|}
\hline Compound & Abbrev. & $\begin{array}{l}\begin{array}{c}\text { Molar mass } \\
\left(\mathrm{g} \cdot \mathrm{mol}^{-1}\right)\end{array} \\
\text { Dispersity } \boxplus\end{array}$ & $\begin{array}{l}\text { Hydrophobic } \\
\text { molar mass a }^{\text {a }} \\
\left(\mathrm{g} \cdot \mathrm{mol}^{-1}\right)\end{array}$ & $\begin{array}{c}\text { Membrane } \\
\text { thickness } \\
\text { (nm) }\end{array}$ \\
\hline $\begin{array}{l}\text { 1-palmitoyl-2-oleoyl-sn- } \\
\text { glycero-3-phosphocholine }\end{array}$ & POPC & $\begin{array}{c}760 \\
-\end{array}$ & - & $4.7 \pm 0.9$ \\
\hline $\mathrm{PDMS}_{23}-b-\mathrm{PEO}_{13}{ }^{33}$ & $\mathrm{Si}_{23} \mathrm{EO}_{13}$ & $\begin{array}{l}2500 \\
1.15\end{array}$ & 1700 & $6.9 \pm 1.0$ \\
\hline PDMS $_{27}-b-\mathrm{PEO}_{17}{ }^{33}$ & $\mathrm{Si}_{27} \mathrm{EO}_{17}$ & $\begin{array}{l}2900 \\
1.11\end{array}$ & 2000 & $8.4 \pm 1.1$ \\
\hline $\mathrm{PDMS}_{36}-b-\mathrm{PEO}_{23}{ }^{33}$ & $\mathrm{Si}_{36} \mathrm{EO}_{23}$ & $\begin{array}{l}4000 \\
1.04\end{array}$ & 2700 & $9.9 \pm 1.6$ \\
\hline
\end{tabular}


Table 1. Molecular characteristics of copolymers and phospholipids used (copolymers names used in previous studies ${ }^{26,34}$ and abbreviations used in this article). ${ }^{a}$ Molar mass determined by ${ }^{1} \mathrm{H}$ NMR. ${ }^{b}$ Membrane thickness determined by SANS in ref 29,33 .

\section{Methods}

\section{Preparation of LUV and LHUV}

The LUVs and LHUVs were prepared by film rehydration process followed by extrusion through a polycarbonate membrane. Briefly, copolymer/phospholipid mixture was prepared in chloroform at a desired ratio. (15\% w/w or $25 \% \mathrm{w} / \mathrm{w}$ of lipid). These ratio were chosen in analogy with previous systematic study ${ }^{29}$ with the idea that a majority in polymer would be more interesting in term of stability for potential application in different fields such as drug delivery or nano reactors. This solution was then vacuum-dried until complete solvent evaporation and re-suspended in an adequate aqueous solution at room temperature (at 2 mg. $\mathrm{mL}^{-1}$ for Cryo-TEM characterization, $1 \mathrm{mg} \cdot \mathrm{mL}^{-1}$ for light scattering studies, $10 \mathrm{mg} \cdot \mathrm{mL}^{-1}$ for SANS studies and permeability measurements). For SANS, mixtures of $\mathrm{D}_{2} \mathrm{O} / \mathrm{H}_{2} \mathrm{O}$ were used to control the contrast variation while for all other measurements, phosphate buffer saline (PBS) solution with an osmolarity of $300 \mathrm{mOsm} . \mathrm{L}^{-1}$ and $\mathrm{pH}=7.4$ was used. Afterwards, the LHUVs were obtained by extrusion (21 times) of this suspension through polycarbonate filters with pore sizes of $100 \mathrm{~nm}$ at room temperature. Details about DLS, CryoTEM, SANS measurements and fitting methodology are available in Electronic Supporting Information.

\section{Dynamic light scattering}

Characterisation of self-assembled nanostructures by dynamic light scattering (DLS) were performed at $20^{\circ} \mathrm{C}$ using a Malvern Zetasizer Nano ZS90, emitting vertically polarized light at $\lambda=632.8 \mathrm{~nm}$ and signal was detected at $90^{\circ}$. The vesicles present a quite narrow size distribution and the data could be treated with the $2^{\text {nd }}$ order cumulant analysis with a relatively $r$ low PDI Index $(<0.2)$. The hydrodynamic radius $\left(R_{H}\right)$ was determined from the apparent diffusion coefficient $(D)$ using the Stokes-Einstein relation $D=k_{\mathrm{B}} T /\left(6 \pi \eta_{\mathrm{S}} R_{\mathrm{H}}\right)$, with $k_{\mathrm{B}}$ the Boltzmann constant and $\eta_{\mathrm{S}}$ the viscosity of the solvent.

\section{Cryo-TEM}

Cryo-TEM preparations and observations: The vitrification of the samples was carried out in a homemade vitrification system. The chamber was held at $22^{\circ} \mathrm{C}$ and the relative humidity at $80 \%$. A $5 \mu \mathrm{L}$ drop of the sample was deposited onto a lacey carbon film covered grid (Ted Pella) rendered hydrophilic using an ELMO glow discharge unit (Cordouan Technologies). The grid is automatically blotted to form a thin film which is plunged in liquid ethane hold at $-190^{\circ} \mathrm{C}$ by liquid nitrogen. In that way, a vitrified film is obtained in which the native structure of the vesicles is preserved. The grid was mounted onto a cryo holder (Gatan 626) and observed under low dose conditions in a Tecnai G2 microscope (FEI) at $200 \mathrm{kV}$. Images were acquired using an Eagle slow scan CCD camera (FEI). 
Small Angle Neutron Scattering measurements:

SANS experiments were carried out on PACE and PAXY spectrometers at Laboratoire Léon Brillouin (CEA Saclay, France). Different configurations were used to reach a scattering vector range $q$ from 0.002 to $0.15 \AA^{-1}$.

Pure lipid or copolymer vesicles were prepared in $\mathrm{D}_{2} \mathrm{O}$ at a concentration of $10 \mathrm{mg} \cdot \mathrm{ml}^{-1}$. For the hybrid vesicles, the contrast variation technique already used in a previous study ${ }^{29,30}$ was performed. Details about the methodology are available in supporting information.

\section{Permeability measurements}

For permeability measurements, the LHUVs were rehydrated in $100 \mathrm{mM}$ fluorescein solution in PBS. For drug loading and release experiments, separation of fluorescein-loaded LHUVs and non-loaded fluorescein molecules was performed by gel filtration column (Sephadex gel, G100) using PBS as eluant in iso-osmolar condition to prevent swelling or shrinking of the vesicles. ${ }^{35}$ Aliquots were collected and presence of LHUVs was followed by DLS at $90^{\circ}$. Aliquots with the higher scattering intensity in DLS (higher concentration in vesicles) were combined to obtain pure fluorescein-loaded LHUV.

The encapsulation efficiency, loading content and permeability were quantified by UV-vis spectroscopy. The results obtained for each sample are the average of three experiments.

In order to measure the fluorescein release over time, an USP 4 apparatus (Sotax CE7 smart with CP 7 piston pump) was used. This device is connected to an UV-vis spectrophotometer (Specord 200 plus, analytikjena). Flow through cells $(22,6 \mathrm{~mm}$ diameter) were used in a closed system. The system was temperature controlled at $25^{\circ} \mathrm{C}$. Briefly, $1 \mathrm{~mL}$ of LHUV suspension was placed in a dialysis bag, which define the volume of the sample $\left(\mathrm{V}_{\text {sample}}\right)$ (Float-A-Lyzer, $100 \mathrm{kDa}$ cut-off) and deposited inside a flow through cell. $80 \mathrm{~mL}$ of PBS were used as release medium at a flow rate of $16 \mathrm{~mL} / \mathrm{min}$. Absorbance of the release medium at $488 \mathrm{~nm}$ (corresponding to the maximum absorbance of fluorescein) was measured continuously during $24 \mathrm{~h}$. The concentration of the released fluorescein was quantified by using the Beer-Lambert law and the calibration curve realized with this spectrophotometer.

The apparent permeability of the membranes was calculated as following, assuming that the diffusion of Fluorescein through vesicle membrane is reversible and rate limiting. ${ }^{36}$ :

$$
P_{\text {app }}=\frac{d c / d t \times V_{\text {sample }} \times[\text { Fluorescein }]_{\text {added }} \times R}{3 \times \Delta C \times[\text { Fluorescein }]_{\text {encapsulated }} \times V_{\text {release medium }}}
$$

With $d c / d t$ the variation with time of the fluorescein concentration outside the vesicles, $V_{\text {sample }}$ the sample volume before dialysis $(1 \mathrm{~mL}),[\text { Fluorescein }]_{\text {added }}$ the fluorescein concentration of the solution used to hydrate films $(100 \mathrm{mM}), \Delta \mathrm{C}$ the fluorescein concentration gradient inside and outside the membrane, [Fluorescein $]_{\text {encapsulated }}$ the fluorescein concentration determined at the end of the release study. The complete release of fluorescein was checked by disrupting the vesicle with addition of Triton X-100. $V_{\text {release medium }}$ is the total volume of the release medium $(80 \mathrm{~mL}) . \mathrm{dc} / \mathrm{dt}$ was estimated in the linear part of the release curves.

The encapsulation efficiency (EE) represents the percentage of fluorescein that is successfully entrapped into the LHUV: 


$$
E E^{\%}=\frac{m_{\text {release }}}{m_{\text {tot } \text { fluo }}} \times 100
$$

With $m_{\text {release }}$ the mass of fluorescein encapsulated in vesicles, determined via the concentration of fluorescein after release experiment in the release medium, and the volume of the release medium, and $m_{\text {tot fluo }}$ the mass of fluorescein contained in the hydration solution.

The loading content (LC) corresponds to the ratio of the mass of encapsulated fluorescein to the copolymer (or copolymer and lipid) mass:

$$
L C^{\%}=\frac{m_{\text {release } 100 \mu l}}{m_{\text {copolymer }}} \times 100
$$

$m_{\text {copolymer }}$ represents the mass of copolymer. It is determined by gravimetry, drying $100 \mu \mathrm{L}$ of the purified vesicle suspension. Therefore, $m_{\text {copolymer }}$ was obtained as:

$$
m_{\text {copolymer }}=m_{\text {tot }}-m_{\text {fluorescein }}-m_{P B S}
$$

With $m_{\text {tot }}$ the total mass obtained by gravimetry, $m_{P B S}$ the mass of buffer solution alone, $m_{\text {fluorescein }}$ the estimated mass of fluorescein encapsulated in the volume considered for gravimetry.

\section{Results and discussion}

\section{Stability of vesicles}

The vesicles obtained by film rehydration and extrusion process were analysed by DLS, after the preparation and after 500 days storage at $4^{\circ} \mathrm{C}$, in order to estimate the stability of the obtained structures. Globally, the hydrodynamic diameters measured by DLS are in agreement with the size of the polycarbonate filters used for extrusion $(100 \mathrm{~nm})$ and present narrow size distribution as illustrated by the low polydispersity index (PDI) values (Supporting Information, Table S1). After 500 days, as illustrated in the Figure 1, the size and size distribution are almost unchanged, excepted for pure POPC vesicles where the size doubles and PDI increases from 0.08 to 0.3 . 
Time ( $\mu \mathrm{s})$

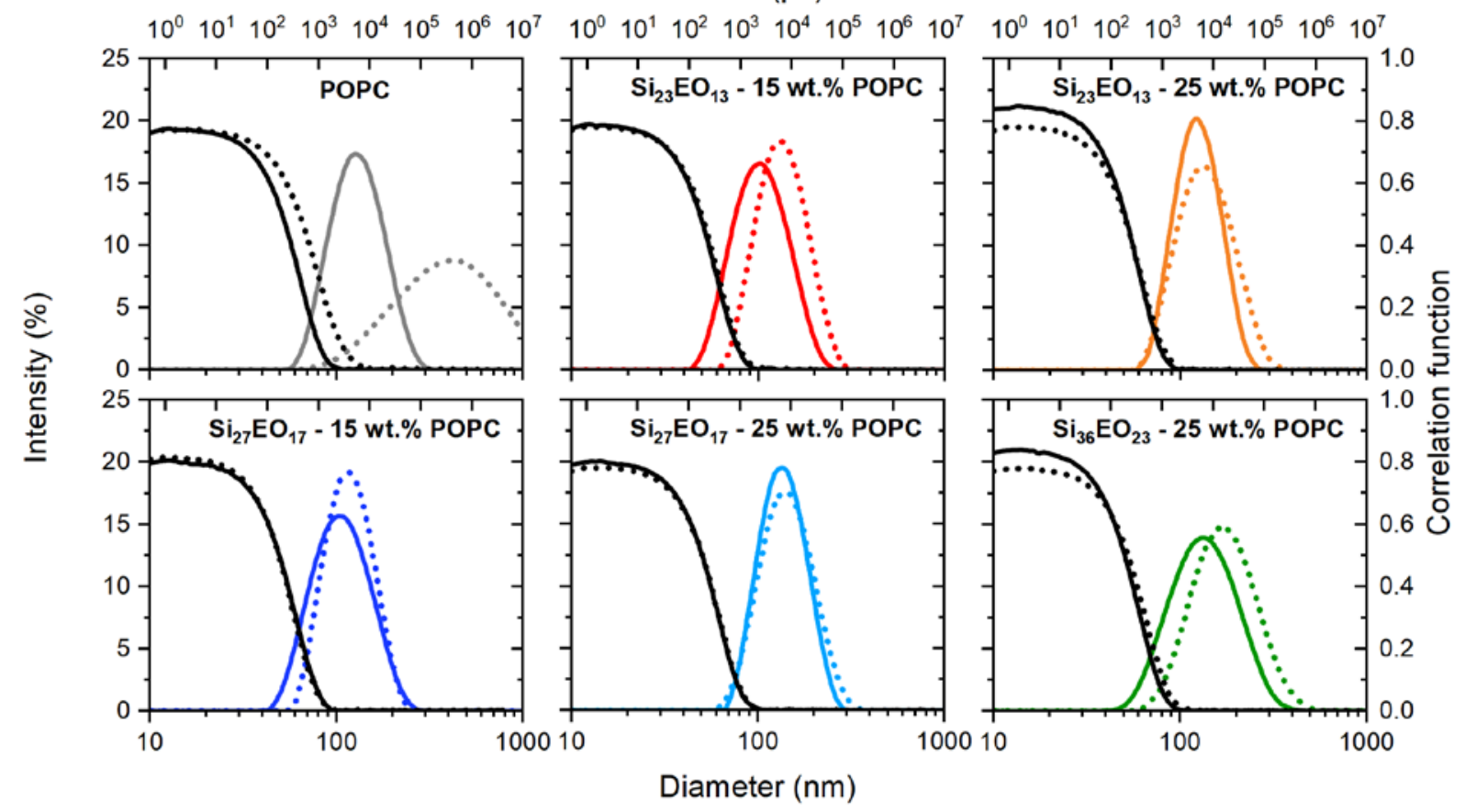

Figure 1: Size distribution (bottom-X; left- $Y$ axis) and autocorrelation function (top-X; right- $Y$ axis) obtained by DLS at $90^{\circ}$, after vesicle formation (solid line) and after 500 days at $4^{\circ} \mathrm{C}$ (dotted lines).

This result illustrates the excellent stability of the polymer/lipid vesicles obtained compared to pure POPC vesicles, with an increase of their size and size distribution that could likely result from the fusion or aggregation of these vesicles over time.

\section{Morphology characterization}

To get more information about the morphology of the obtained nanostructures, Cryo-TEM experiments were performed with all block copolymers referenced in Table 1, in association with POPC at 15\% w/w content. Cryo-TEM has been performed on the pure polymersomes in a previous study. ${ }^{33}$

For the system with the lower molar mass copolymer $\mathrm{Si}_{23} \mathrm{EO}_{13} / \mathrm{POPC}$, two main morphologies are observed as shown in Figure 2. The main population is constituted of vesicles with a membrane thickness of $8.3 \pm 1.1 \mathrm{~nm}$ (Figure 2-B). This thickness value is slightly below the one of pure polymersomes $(8.6 \pm 1.1 \mathrm{~nm})$. Therefore, this population may correspond to pure polymersomes or hybrid vesicles in which lipid is homogeneously dispersed in the polymer membrane. The second but minor population consists in vesicles with a membrane thickness of $5.5 \mathrm{~nm}$, for which a bilayer structure is visible, typical of phospholipid vesicles (Figure 2-C). 

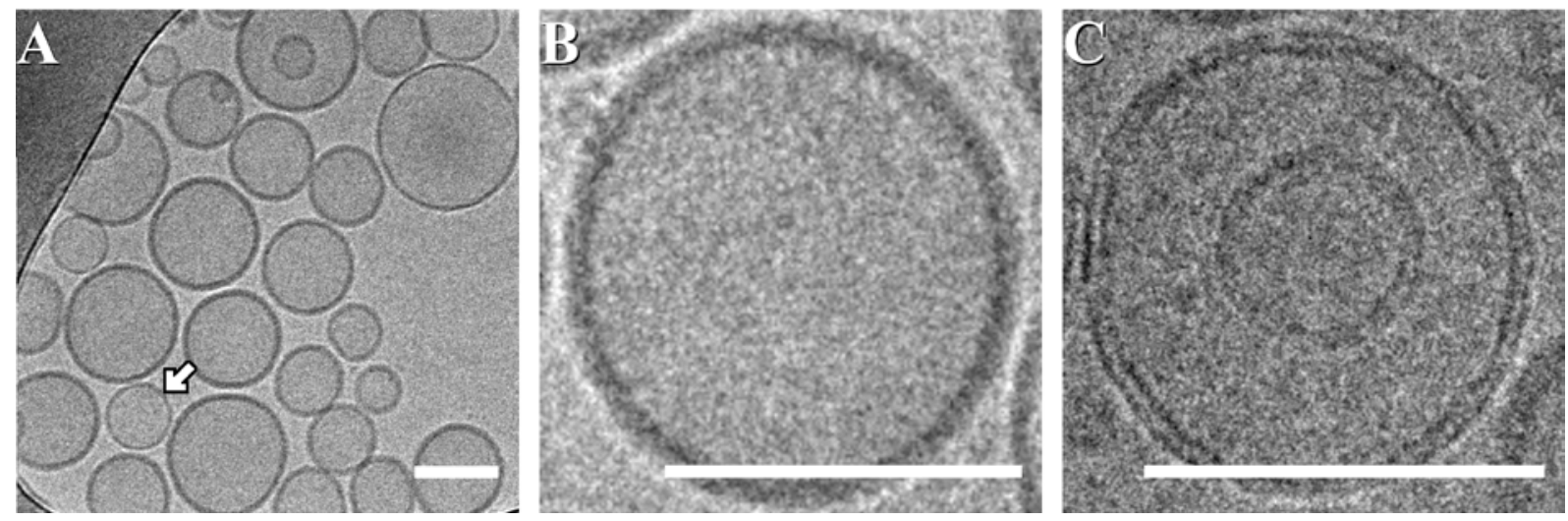

Figure 2: Cryo-TEM pictures of the $85 / 15$ w/w $\mathrm{Si}_{23} \mathrm{EO}_{13} / \mathrm{POPC}$ sample. A- Representative picture of the population observed. Vesicle indicated with a white arrow corresponds to vesicle presenting a bilayer. B- Enlargement of vesicle presenting membrane thickness of $8.3 \mathrm{~nm}$. C- Vesicle with bilayer signature. White scale bars represent $100 \mathrm{~nm}$.

Interestingly, for the system with a higher molar mass copolymer $\mathrm{Si}_{27} \mathrm{EO}_{17} / \mathrm{POPC}$, only vesicles with a thick uniform membrane are observed (Figure 3). The average membrane thickness is $10.2 \pm 1.0 \mathrm{~nm}$, which is close to the one reported for pure polymersomes $(10.0 \pm 1.0 \mathrm{~nm})$. The absence of vesicle with a bilayer membrane excludes the presence of liposomes and therefore suggests an effective mixture between the copolymer and the lipid. The absence of lipid domains, characterized by a thinner membrane, suggests that the lipid is homogeneously distributed in the membrane.
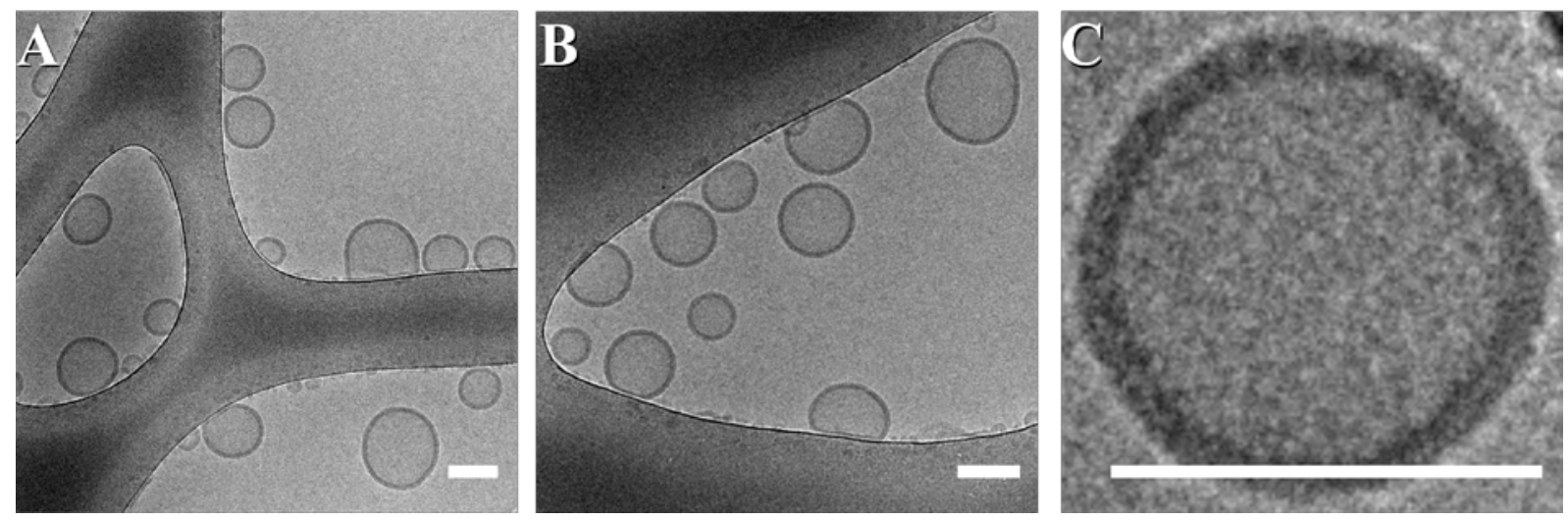

Figure 3: CryoTEM pictures of the 85/15 w/w Si27 EO $17 / P O P C$ sample. A, B- Representative pictures of the population observed. $\mathbf{C}$ - Enlargement showing the characteristic thick membrane of the vesicles. White scale bars represent $100 \mathrm{~nm}$.

Finally, the system with the highest molar mass copolymer $\mathrm{Si}_{36} \mathrm{EO}_{23} / \mathrm{POPC}$, presents mostly vesicular structures (Figure 4-A and $\mathrm{B}$ ). Among the present vesicles, mainly homogeneous membranes are observed (Figure 4-A, B and C). A small fraction of vesicles has a bilayer membrane (Figure 4-A and D). Tubular elongated structures are also observed (Figure 4-B). The thickness of both types of membrane was measured on a few objects. For solid membranes, a thickness of $11.9 \pm 1.5 \mathrm{~nm}$ is measured, slightly less than that obtained for $\mathrm{Si}_{36} \mathrm{EO}_{13}$ polymersomes $(13.1 \pm 1.5 \mathrm{~nm})$. The bilayer membranes have a thickness of $6.0 \mathrm{~nm}$, close to that of liposomes. 

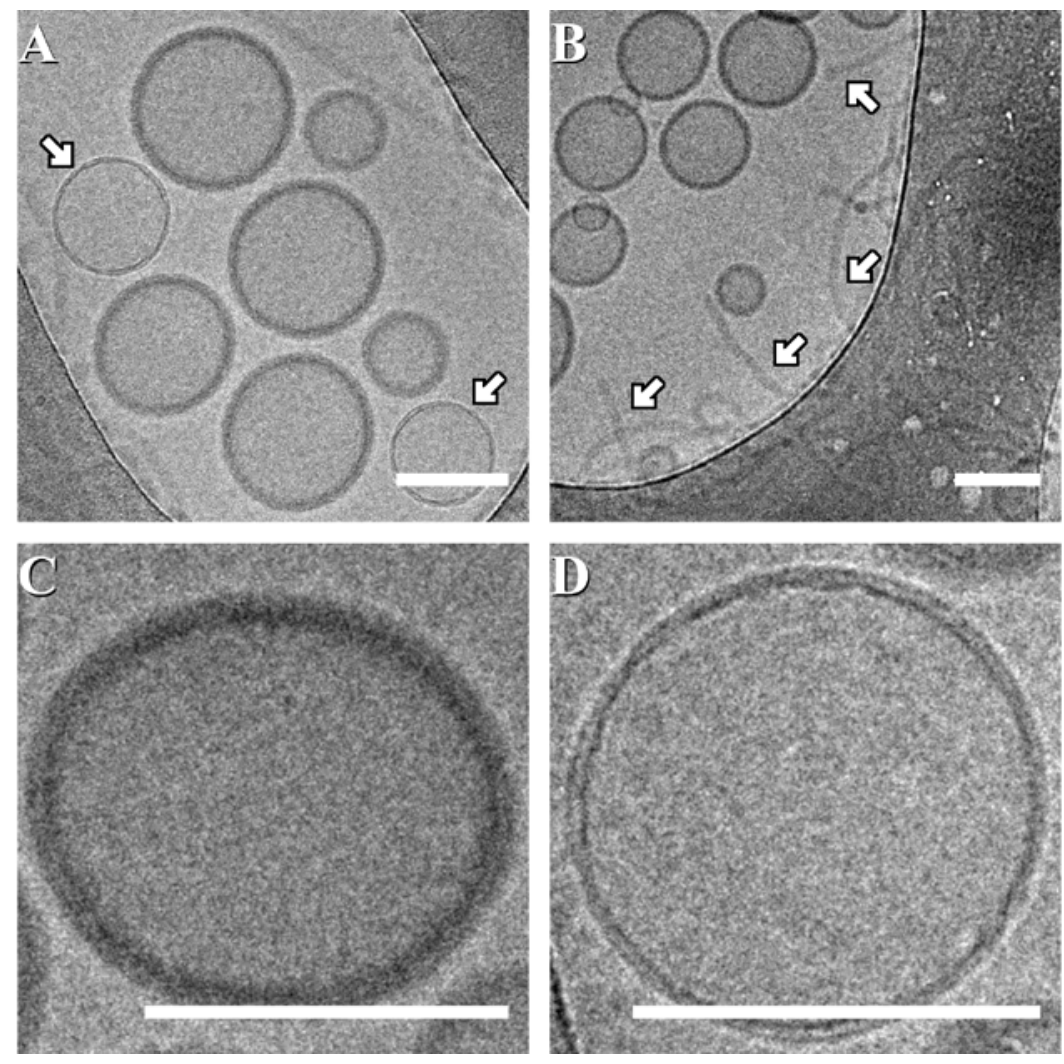

Figure 4: Cryo-TEM pictures of the 85/15 w/w Si ${ }_{36} \mathrm{EO}_{23} / \mathrm{POPC}$ sample. A- Characteristic image obtained for this sample. The presence of vesicles with a bilayer membrane is indicated by white arrows. BPicture showing the coexistence of the vesicle with tubular structures (white arrows). C- Characteristic image of the majority of vesicles in the sample, characterized by a thick membrane. D- Characteristic image of a vesicle in the sample characterized by a bilayer membrane. White scale bars correspond to $100 \mathrm{~nm}$.

To conclude on this part, the formation of vesicles from a mixture of diblock PDMS- $b$-PEO copolymer and POPC was confirmed by Cryo-TEM. Vesicular structures were observed for all three systems using 15\% w/w POPC. A small population of elongated tubular structures were also observed, with the highest molar mass copolymer $\left(\mathrm{Si}_{36} \mathrm{EO}_{13}\right)$. It seems that these morphologies are frequently observed when phospholipids and copolymers of high molar mass are associated to generate LHUV, ${ }^{24,29}$ The mechanism of their formation is still unknown so far. The vesicles prepared from $\mathrm{Si}_{23} \mathrm{EO}_{13}$ and $\mathrm{Si}_{36} \mathrm{EO}_{23}$ copolymers present two types of membranes: mostly homogeneous membranes, but also a small fraction of membranes with a bilayer organization, which could be attributed to the formation of liposomes. Vesicles with thick membranes can be hybrid vesicles with a homogeneous membrane or pure polymersomes. However, given the initial lipid/polymer composition and the small number of lipid vesicles observed, it is likely that a large number of these vesicles are hybrid vesicles. In addition, for vesicles prepared from $\mathrm{Si}_{36} \mathrm{EO}_{23} / \mathrm{POPC}$, the average membrane thickness is thinner than the one of pure polymersomes, which may be an indication of their hybrid character. It has to be noted that a decrease in membrane thickness has already been observed for PDMS- $b$-PMOXA vesicles upon addition of a small amount of cholesterol, resulting in a modification of packing density of the molecules in the membranes. ${ }^{28}$ 


\section{Membrane homogeneity in LHUV observed by SANS}

To get more information about the hybrid character of the vesicles obtained and their membrane structure, we used SANS with a contrast variation technique to selectively detect the signal of either the lipid, the polymer phase or all together. We studied the hybrid vesicles at two different compositions, 15 and $25 \% \mathrm{w} / \mathrm{w}$ of POPC.

All the curves obtained in full contrast condition could be fitted with a vesicle form factor, as expected from the Cryo-TEM results (SI, Figure S1). The elongated structures observed occasionally in Cryo-TEM for the $\mathrm{Si}_{36} \mathrm{EO}_{13} / \mathrm{POPC}$ were not detected by SANS, attesting their weak proportion. Sizes deduced from the fit to the vesicle form factor are in good agreement with DLS and Cryo-TEM results (Table S2), attesting of the vesicular morphologies.

To prove the hybrid character, we have studied the vesicle suspension in lipid contrast and polymer contrast conditions following a method described in a previous study ${ }^{29}$ and summarized in the SI. In both conditions, the SANS curves obtained could be again fitted with a simple vesicle form factor (Figure 5). In our previous study on triblock copolymers, in polymer contrast, data could only be fitted with a perforated vesicle form factor in the case of low mass triblock copolymers, while in lipid contrast the data were fitted reasonably well with a disk form factor. ${ }^{29}$ This was due to the presence of lipid nanodomains in the vesicle. Here, we were able to fit the data by a simple vesicle form factor, which allows to exclude a lateral phase separation in the membrane. One can suppose that we could have pure polymersomes with some pure liposomes, but this hypothesis is unlikely: first by observing the membranes of all the vesicles by Cryo-TEM and then looking at the fitted parameters which will be detailed now.

15 wt. \% POPC - Lipid visible [I x1]
15 wt.\% POPC - Polymer visible [I x1]

25 wt.\% POPC - Lipid visible [I x20]

25 wt. \% POPC - Polymer visible [I x20]

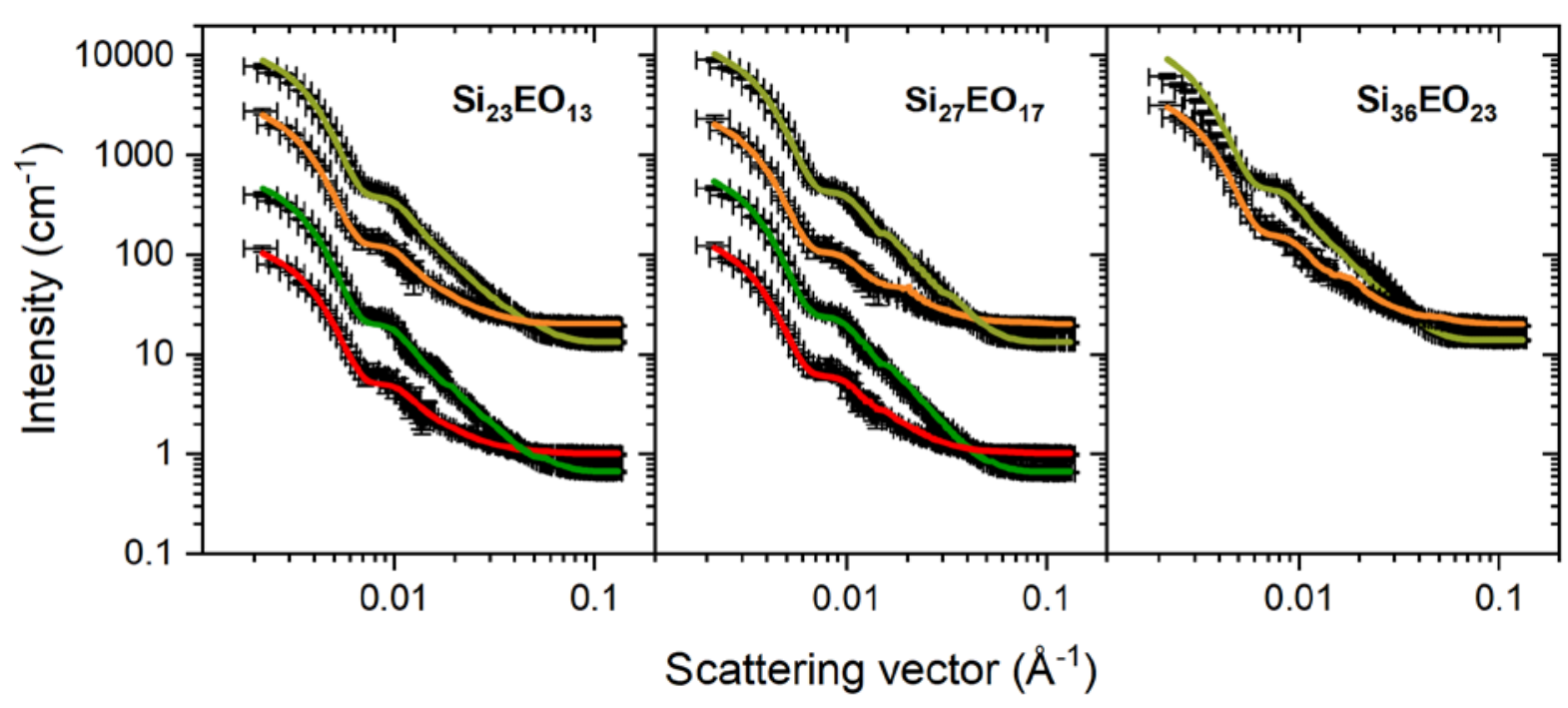

Figure 5: SANS curves in polymer contrast and lipid contrast conditions, for LHUVs composed of $\mathrm{Si}_{23} \mathrm{EO}_{13}, \mathrm{Si}_{27} \mathrm{EO}_{17}$ and $\mathrm{Si}_{36} \mathrm{EO}_{23}$ and POPC. The data are adjusted by the vesicle form factor (colored lines). The intensity is shifted by the factor indicated in the figure caption for visibility.

Regarding the fitting methodology, scattered intensity in lipid contrast condition was relatively weak. Several parameters set (volume fraction/ radius/ membrane thickness and dispersity) 
could be used to fit the data as reported in Table $\mathrm{S} 3(\mathrm{SI})$ and led to the same fit quality. Therefore, the Kratky-Porod plot $\left(\mathrm{Ln}\left(\mathrm{Iq}^{2}\right)\right.$ vs. $\left.\mathrm{q}^{2}\right)$ was used to have an average value of the membrane thickness. For a lamella of thickness $\delta$, the intermediate $q$ Guinier approximation of the scattering intensity is defined as:

$$
\begin{gathered}
I(q)=\frac{I(0)}{Q^{2}} \exp \left(-\frac{q^{2} R_{g}^{2}}{1}\right) \\
\text { where } R_{g}^{2}=\frac{\delta^{2}}{12}
\end{gathered}
$$

Plots are available in SI, Figure S2. Values of membrane thickness thus obtained are indicated in Table 2. They are in between 5-7 nm close to the one obtained for pure lipid membrane (4.7 $\mathrm{nm})$, whatever the lipid fraction used.

\begin{tabular}{|c|c|c|}
\hline \multirow{2}{*}{ Sample } & $\begin{array}{c}\text { Lipid fraction } \\
(\% \mathrm{w} / \mathrm{w}-\% \text { mol/mol) }\end{array}$ & $\begin{array}{c}\text { Lipid phase thickness }(\mathrm{nm}) \\
\text { (Kratky-Porod) }\end{array}$ \\
\hline \multirow{2}{*}{$\mathrm{Si}_{23} \mathrm{EO}_{13}$} & $15-36.7$ & 6.8 \\
\cline { 2 - 3 } & $25-52.3$ & 6.0 \\
\hline \multirow{2}{*}{$\mathrm{Si}_{27} \mathrm{EO}_{17}$} & $15-40.2$ & 6.4 \\
\hline $\mathrm{Si}_{36} \mathrm{EO}_{23}$ & $25-56$ & 6.6 \\
\hline
\end{tabular}

Table 2: Membrane thickness obtained by the Krakty-Porod fit in lipid contrast condition.

These values of membrane thickness were therefore set as a fixed parameter in the vesicle form factor fit. Volume fraction, radii and distribution were then determined by the fit. The values obtained are indicated in SI, Table S4-S6. The thickness determined in polymer contrast condition and in lipid contrast condition corresponds respectively to the membrane thickness of the polymer phase and of the lipid phase. The evolution of the membrane thickness with lipid fraction is illustrated in Figure 6 . When observing the polymer phase, the membrane thickness decreases with POPC fraction, as it was observed in Cryo-TEM: this suggests interactions between polymer chains and phospholipids and consequently homogeneous distribution of lipid in the polymer membrane. The higher the molar mass of the copolymer, the greater is the contraction of the chains in the membrane. When observing the POPC phase, in the case of $\mathrm{Si}_{23} \mathrm{EO}_{23}$ and $\mathrm{Si}_{27} \mathrm{EO}_{17}$, larger thicknesses between 6 and $6.8 \mathrm{~nm}$ are obtained. Again, this result is a proof of strong interactions and mixing between lipid and polymer. However, for $\mathrm{Si}_{36} \mathrm{EO}_{23}$, the membrane thickness value $4.8 \mathrm{~nm}$ is relatively close to the one obtained for pure liposomes $(4.7 \mathrm{~nm})$ and could suggest fission in the sample (polymersomes and liposomes), but in this case, the thickness of the polymer phase should also remain unchanged, which is not observed. 


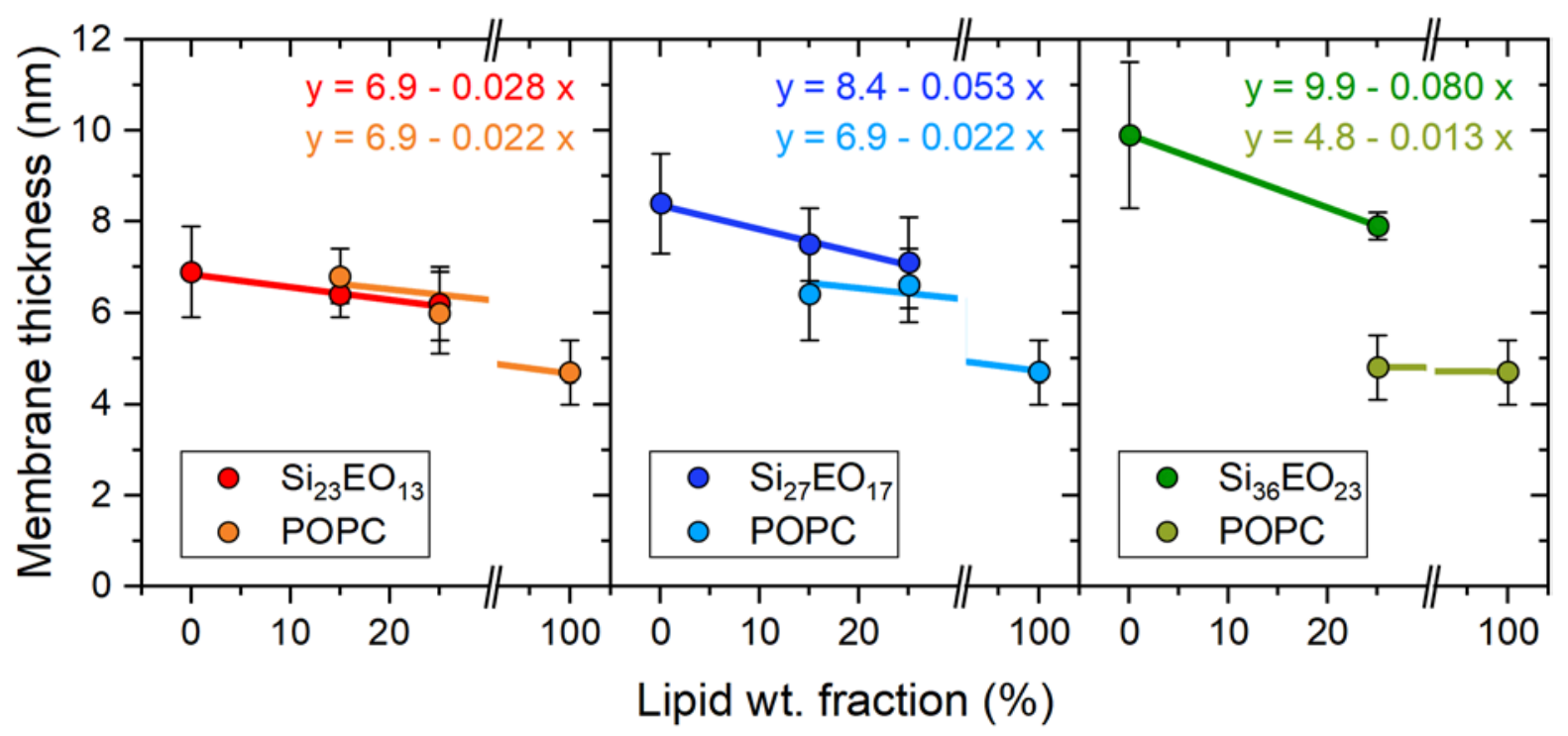

Figure 6: Representation of the membrane thicknesses of copolymers and POPC as a function of POPC fractions. The data are adjusted by linear regression (colored lines).

Globally the SANS data in the different contrast conditions are in agreement with the CryoTEM observations. Vesicular morphology is obtained independently of the molar mass of the copolymer used. The evolution of the membrane thickness in polymer and lipid contrast conditions suggests interactions between polymer and lipid phase, and therefore a hybrid character. In addition, the fact that data could be fitted with simple vesicle form factor indicates the formation of vesicle with homogeneous distribution of components in the membrane.

It is worth noting that a simple change in architecture of the copolymer, diblock or triblock able to form vesicles with comparable membrane thicknesses, leads to different membrane structures. Whereas lipid nanodomains have been evidenced in LHUV formulated with PEO$b$-PDMS- $b$-PEO triblock copolymer and phospholipid in a fluid state ${ }^{29}$, the use of diblock copolymers of same chemical nature leads to LHUV homogeneous membrane structure.

\section{Permeability measurements}

In order to evaluate the membrane permeability of these vesicles, fluorescein was encapsulated inside the different LHUVs, and their permeability have been estimated through the measurement of the amount of fluorescein released from vesicle over time. Encapsulation efficiency and loading content have been also estimated.

The evolution of the amount of fluorescein released has been first studied for all pure liposomes and polymersomes (Figure 7-A). The raw data representing the absorbance over time are available in SI, Figure S4. 


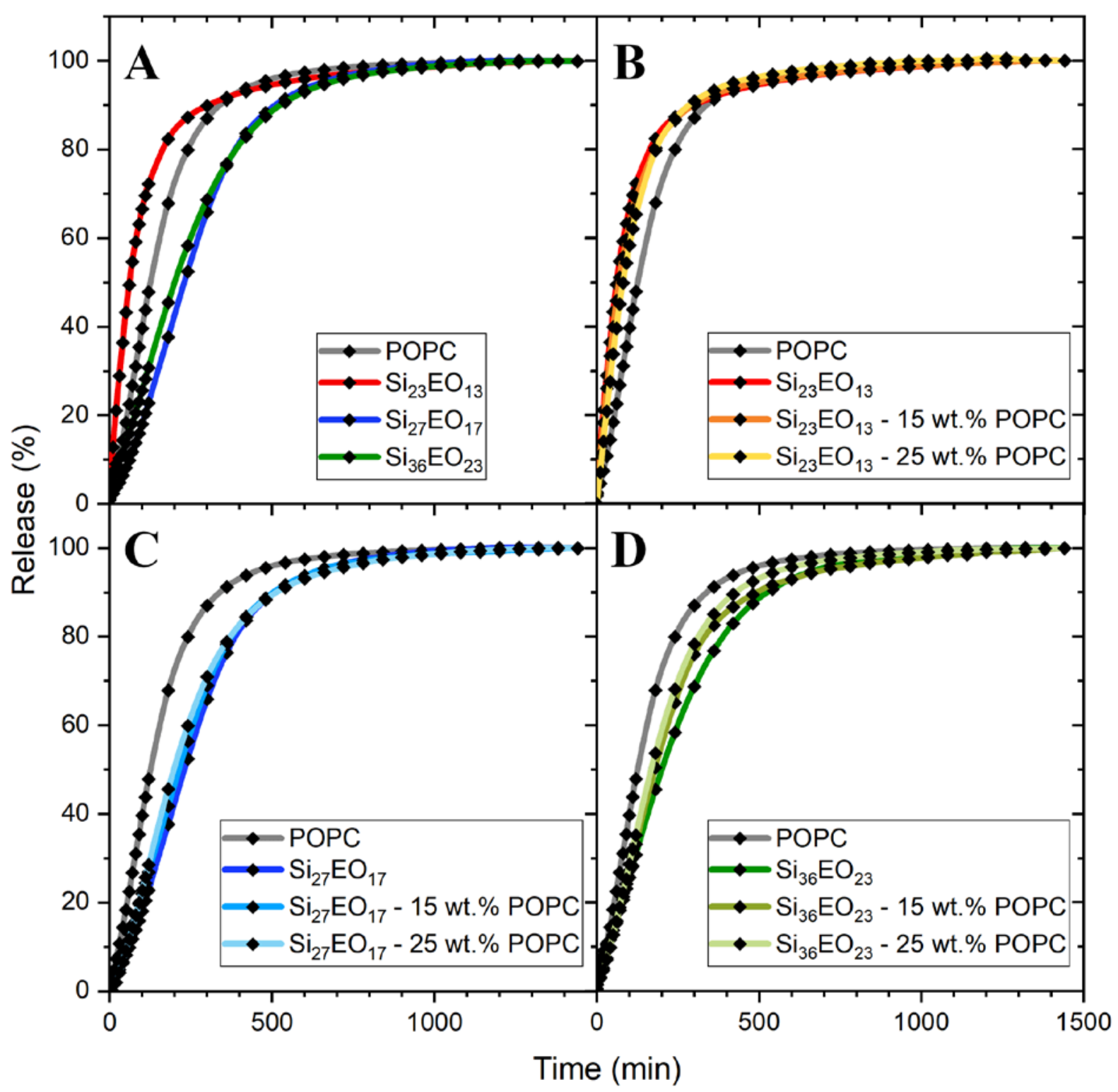

Figure 7: Fluorescein release experiments. A- Release profiles from vesicles composed of pure POPC (grey line), $\mathrm{Si}_{23} \mathrm{EO}_{13}$ (red line), $\mathrm{Si}_{27} \mathrm{EO}_{17}$ (blue line) and $\mathrm{Si}_{36} \mathrm{EO}_{23}$ (green line). B- Release profiles from vesicles composed of pure POPC (grey line), $\mathrm{Si}_{23} \mathrm{EO}_{13}$ (red line), $\mathrm{Si}_{23} \mathrm{EO}_{13} / \mathrm{POPC} 85 / 15 \mathrm{w} / \mathrm{w}$ (orange line) and $\mathrm{Si}_{23} \mathrm{EO}_{13} / \mathrm{POPC} 75 / 25 \mathrm{w} / \mathrm{w}$ (yellow line). C- Release profiles from vesicles composed of pure POPC (grey line), $\mathrm{Si}_{27} \mathrm{EO}_{17}$ (darker blue line), $\mathrm{Si}_{27} \mathrm{EO}_{17} / \mathrm{POPC} 85 / 15 \mathrm{w} / \mathrm{w}$ (blue line) and $\mathrm{Si}_{27} \mathrm{EO}_{17} / \mathrm{POPC}$ $85 / 15 \mathrm{w} / \mathrm{w}$ (lighter blue line). D- Release profiles from vesicles composed of pure POPC (grey line), $\mathrm{Si}_{36} \mathrm{EO}_{23}$ (darker green line), $\mathrm{Si}_{36} \mathrm{EO}_{23} / \mathrm{POPC} 85 / 15 \mathrm{w} / \mathrm{w}$ (green line) and $\mathrm{Si}_{36} \mathrm{EO}_{23} / \mathrm{POPC}$ 85/15 w/w (lighter green line).

The values of permeability as well as the loading content and encapsulation efficiency are illustrated in Table 3. 


\begin{tabular}{|c|c|c|c|}
\hline Sample & $\begin{array}{l}\text { Permeability } \\
\left(10^{-9} \mathrm{~nm}^{\left.-\mathrm{s}^{-1}\right)}\right.\end{array}$ & $\begin{array}{l}\text { Encapsulation } \\
\text { efficiency (\%) }\end{array}$ & $\begin{array}{l}\text { Loading } \\
\text { content (\%) }\end{array}$ \\
\hline POPC & $1.88 \pm 0.17$ & 0.32 & 4.86 \\
\hline $\mathrm{Si}_{23} \mathrm{EO}_{13}$ & $2.74 \pm 0.20$ & 0.15 & 4.44 \\
\hline $\mathrm{Si}_{27} \mathrm{EO}_{17}$ & $1.20 \pm 0.11$ & 0.17 & 4.97 \\
\hline $\mathrm{Si}_{36} \mathrm{EO}_{23}$ & $1.22 \pm 0.14$ & 0.12 & 2.96 \\
\hline $\begin{aligned} & \mathrm{Si}_{23} \mathrm{EO}_{13} \\
+ & 15 \% \mathrm{POPC}\end{aligned}$ & $2.18 \pm 0.07$ & 0.11 & 4.24 \\
\hline $\begin{aligned} & \mathrm{Si}_{23} \mathrm{EO}_{13} \\
+ & 25 \% \mathrm{POPC}\end{aligned}$ & $2.37 \pm 0.10$ & 0.09 & 4.85 \\
\hline $\begin{aligned} & \mathrm{Si}_{27} \mathrm{EO}_{17} \\
+ & 15 \% \text { POPC }\end{aligned}$ & $1.04 \pm 0.03$ & 0.11 & 2.14 \\
\hline $\begin{aligned} & \mathrm{Si}_{27} \mathrm{EO}_{17} \\
+ & 25 \% \text { POPC }\end{aligned}$ & $0.94 \pm 0.05$ & 0.08 & 3.17 \\
\hline $\begin{aligned} & \mathrm{Si}_{36} \mathrm{EO}_{23} \\
+ & 15 \% \mathrm{POPC}\end{aligned}$ & $1.18 \pm 0.03$ & 0.07 & 1.18 \\
\hline $\begin{aligned} & \mathrm{Si}_{36} \mathrm{EO}_{23} \\
+ & 25 \% \text { POPC }\end{aligned}$ & $1.37 \pm 0.12$ & 0.12 & 3.73 \\
\hline
\end{tabular}

Table 3: Permeability, encapsulation efficiency and loading content obtained for pure liposomes, pure polymersomes and hybrid vesicles.

The low encapsulation efficiency values obtained are inherent to the film hydration, which is a passive encapsulation process. The inner vesicular volume is very small compared to the entire volume of the sample. Concerning the loading content, the obtained values, around 3 to $5 \%$, are relatively classical for such encapsulation procedure. ${ }^{37,38}$

As expected, the permeability of pure lipid vesicles is higher than pure copolymer vesicles, except for the lowest molar mass copolymer $\left(\mathrm{Si}_{23} \mathrm{EO}_{13}\right)$. This latter presents a permeability value considerably higher, despite a higher membrane thickness (6.9 nm instead of $4.7 \mathrm{~nm}$ for pure POPC liposomes). It has been recognized in literature that the permeability of the polymersomes is modulated by their membrane thickness and that it is much lower than the one of liposomes. ${ }^{2,36,39-41}$ However, the variety of block copolymer used to study their membrane permeability is far more restricted than the variety of phospholipids used. It has to be noted that quantitative studies of vesicles permeability are scarce because of technical difficulties that are nicely summarized in a recent study of Castiglione and col..$^{42}$ Quantitative value of permeability for simple solute (water, protons) can be found so far only for membrane constituted of hydrophobic blocks such as polybutadiene, ${ }^{39,43}$ polybutylene oxide ${ }^{36}$ or polycaprolactone. ${ }^{40}$ Permeability to various molecules has also been estimated in polymersomes made of triblock PMOXA- $b$-PDMS- $b$-PMOXA copolymers. ${ }^{42}$ Therefore this result for $\mathrm{Si}_{23} \mathrm{EO}_{13}$ shows that care has to be taken before considering polymersomes far more 
impermeable than liposomes as « universal », chemical nature of the copolymer as well as its architecture is of importance.

Concerning the hybrid systems, the release profiles are represented in Figure 7- B, C and D. The release profiles of pure liposome and polymersome are represented as reference. The values of the permeability as well as the loading content and encapsulation efficiency are illustrated in Table 3.

In the case of hybrid vesicles constituted with the lowest molar mass copolymer $\left(\mathrm{Si}_{23} \mathrm{EO}_{13}\right)$, the permeability seems to be intermediate between those of pure liposomes and those of pure polymersomes. In that case, the permeability of polymersomes $\mathrm{Si}_{23} \mathrm{EO}_{13}$ which is higher than POPC liposomes, decreases when lipid is added. However, for polymersomes with higher membrane thicknesses $\left(\mathrm{Si}_{27} \mathrm{EO}_{17}\right.$ and $\left.\mathrm{Si}_{36} \mathrm{EO}_{23}\right)$ that present permeabilities a bit lower than pure liposomes, the permeability does not seem to be affected in a significant way.

This very weak influence of lipid content on the permeability of the polymersomes may be in relation with the absolute differences in terms of permeabilities between pure POPC vesicles and SixEOy polymersomes which were surprisingly low for $\mathrm{Si}_{23}$ and $\mathrm{Si}_{27}$. Therefore even is the membrane Is modified as illustrated by the membrane thicknesses evolution revealed by SANS, when lipids are incorporated, this may not facilitate a precise measurement of intermediate permeability between pure polymersomes and liposomes. However our measurements clearly show that a permeability greater than the pure liposomes, which has already been obtained in literature ${ }^{13,32}$ is definitely to discard. Such a greater permeability may be related to the presence of heterogeneities (raftlike domain) in the membrane, but this has not been quantified yet.

\section{Conclusion}

In this work, Large Hybrid Unilamellar Vesicles (LHUV) were obtained from the association of PDMS- $b$-PEO diblock copolymers with different molar masses and a phospholipid (POPC) in a fluid state. In all cases, LHUVs were obtained in the polymer/ lipid composition (up to 25\% $w / w$ in lipid) investigated with homogeneous distribution of lipid in the polymer membrane as revealed by Cryo-TEM and SANS experiments. This work reveals the importance of polymer chains conformation in the membrane of hybrid vesicles. Indeed, for triblock copolymer PEO$b$-PDMS- $b$-PEO, studied in a previous work, that presents according to a work of Itel et al. ${ }^{44}, a$ mixture of hairpin and extended chain conformation in the membrane, the lipid distribution is not homogenous and presence of lipid nanodomains in the vesicle has been revealed. ${ }^{29}$ The diblock copolymers used in this study form membrane with a conformation closer from the lipid bilayer conformation, which help the lipid to disperse homogeneously in the membrane. This leads to LHUVs with a permeability intermediate between those of liposomes and polymersomes. Future work could consist in a fine analysis of membrane structure of LHUV for which higher permeability than pure liposomes has been observed ${ }^{13}$, and establish a correlation with the eventual presence of domain, as it was suggested in hybrid polymer/lipid planar films ${ }^{32}$.

\section{Acknowledgements}

M. Fauquignon gratefully acknowledges the Scientific Department of University of Bordeaux for a PhD fellowship. 


\section{Declaration of competing interest}

There is no competing interest to declare

\section{Authors contribution}

Martin Fauquignon: All experiments and data analysis, manuscript review.

Elise Courtecuisse: Drug release and permeability measurements.

Romane Josselin: Drug release and permeability measurements, manuscript review.

Angela Mutschler: Drug release and permeability analysis, manuscript review.

Annie Brûlet: SANS experiments analysis, manuscript review.

Marc Schmutz: CryoTEM experiments and analysis, manuscript review.

Jean- François Le Meins: Funding acquisition, supervision, methodology, manuscript writing.

\section{REFERENCES}

2018, 7.

(1) Leong, J.; Teo, J. Y.; Aakalu, V. K.; Yang, Y. Y.; Kong, H. Advanced Healthcare Materials

(2) Le Meins, J. F.; Sandre, O.; Lecommandoux, S. Eur. Phys. J. E 2011, 34, 14.

(3) Discher, B. M.; Hammer, D. A.; Frank, S. B.; Discher, D. E. Current Opinion in Colloid \& Interface Science 2000, 5, 125.

(4) Discher, B. M.; Won, Y. Y.; Ege, D. S.; Lee, J. C. M.; Bates, F. S.; Discher, D. E.; Hammer, D. A. Science 1999, 284, 1143.

(5) Le Meins, J. F.; Schatz, C.; Lecommandoux, S.; Sandre, O. Mater. Today 2013, 16, 397.

(6) Schulz, M.; Binder, W. H. Macromol. Rapid Comm. 2015, 36, 2031.

(7) Krywko-Cendrowska, A.; di Leone, S.; Bina, M.; Yorulmaz-Avsar, S.; Palivan, C. G.; Meier, W. Polymers 2020, 12, 1003.

(8) Kleineberg, C.; Wolfer, C.; Abbasnia, A.; Pischel, D.; Bednarz, C.; Ivanov, I.; Heitkamp, T.; Borsch, M.; Sundmacher, K.; Vidakovic-Koch, T. Chembiochem 2020.

(9) Nishimura, T.; Hirose, S.; Sasaki, Y.; Akiyoshi, K. J Am Chem Soc 2020, 142, 154.

(10) Di Leone, S.; Avsar, S. Y.; Belluati, A.; Wehr, R.; Palivan, C. G.; Meier, W. J Phys Chem B 2020, 124, 4454.

(11) Zhang, Y.; Gal, N.; Itel, F.; Westensee, I. N.; Brodszkij, E.; Mayer, D.; Stenger, S.; Castellote-Borrell, M.; Boesen, T.; Tabaei, S. R.; Höök, F.; Städler, B. Nanoscale 2019, 11, 11530.

(12) Beales, P. A.; Khan, S.; Muench, S. P.; Jeuken, L. J. C. Biochem. Soc. Trans. 2017, 45, 15.

(13) Paxton, W. F.; McAninch, P. T.; Achyuthan, K. E.; Shin, S. H. R.; Monteith, H. L. Colloids Surf. B 2017, 159, 268.

(14) Seneviratne, R.; Khan, S.; Moscrop, E.; Rappolt, M.; Muench, S. P.; Jeuken, L. J. C.; Beales, P. A. Methods 2018, 147, 142.

(15) Khan, S.; Li, M.; Muench, S. P.; Jeuken, L. J. C.; Beales, P. A. Chem. Commun. 2016, 52, 11020.

(16) Khan, S.; McCabe, J.; Hill, K.; Beales, P. A. J Colloid Interface Sci 2020, 562, 418.

(17) Mumtaz Virk, M.; Reimhult, E. Langmuir 2018, 34, 395. 
(18) Pippa, N.; Merkouraki, M.; Pispas, S.; Demetzos, C. Int J Pharm 2013, 450, 1.

(19) Lim, S.; de Hoog, H.-P.; Parikh, A.; Nallani, M.; Liedberg, B. Polymers 2013, 5, 1102.

(20) Pippa, N.; Stellas, D.; Skandalis, A.; Pispas, S.; Demetzos, C.; Libera, M.; Marcinkowski, A.; Trzebicka, B. Eur J Pharm Biopharm 2016, 107, 295.

(21) Panneerselvam, K.; Lynge, M. E.; Riber, C. F.; Mena-Hernando, S.; Smith, A. A.; Goldie, K. N.; Zelikin, A. N.; Stadler, B. Biomicrofluidics 2015, 9, 052610.

(22) Cheng, Z.; Elias, D. R.; Kamat, N. P.; Johnston, E.; Poloukhtine, A. A.; Popik, V. V.; Hammer, D. A.; Tsourkas, A. Bioconjugate Chem. 2011, 22, 2021.

(23) Schulz, M.; Werner, S.; Bacia, K.; Binder, W. H. Angew Chem Int Ed Eng/ 2013, 52, 1829.

(24) Lim, S. K.; Wong, A. S. W.; de Hoog, H.-P. M.; Rangamani, P.; Parikh, A. N.; Nallani, M.; Sandin, S.; Liedberg, B. Soft Matter 2017, 13, 1107.

(25) Hu, S.-W.; Huang, C.-Y.; Tsao, H.-K.; Sheng, Y.-J. Physical Review E 2019, 99, 012403.

(26) Dao, T. P. T.; Fernandes, F.; Ibarboure, E.; Ferji, K.; Prieto, M.; Sandre, O.; Le Meins, J.F. Soft Matter 2017, 13, 627.

(27) Magnani, C.; Montis, C.; Mangiapia, G.; Mingotaud, A. F.; Mingotaud, C.; Roux, C.; Joseph, P.; Berti, D.; Lonetti, B. Colloids Surf. B 2018, 168, 18.

(28) Winzen, S.; Bernhardt, M.; Schaeffel, D.; Koch, A.; Kappl, M.; Koynov, K.; Landfester, K.; Kroeger, A. Soft Matter 2013, 9, 5883.

(29) Dao, T. P. T.; Brûlet, A.; Fernandes, F.; Er-Rafik, M.; Ferji, K.; Schweins, R.; Chapel, J. P.; Fedorov, A.; Schmutz, M.; Prieto, M.; Sandre, O.; Le Meins, J. F. Langmuir 2017, 33, 1705.

(30) Dao, T. P. T.; Fernandes, F.; Er-Rafik, M.; Salva, R.; Schmutz, M.; Brulet, A.; Prieto, M.; Sandre, O.; Le Meins, J. F. ACS Macro Letters 2015, 4, 182.

(31) Rottet, S.; Iqbal, S.; Beales, P. A.; Lin, A.; Lee, J.; Rug, M.; Scott, C.; Callaghan, R. Polymers 2020, 12, 1049.

(32) Kang, M.; Lee, B.; Leal, C. Chemistry of Materials 2017, 29, 9120.

(33) Fauquignon, M.; Ibarboure, E.; Carlotti, S.; Brûlet, A.; Schmutz, M.; Le Meins, J.-F. Polymers 2019, 11, 2013.

(34) Dao, T. P. T.; Fernandes, F.; Fauquignon, M.; Ibarboure, E.; Prieto, M.; Le Meins, J. F. Soft Matter 2018, 14, 6476.

(35) Salva, R.; Le Meins, J.-F.; Sandre, O.; Brûlet, A.; Schmutz, M.; Guenoun, P.; Lecommandoux, S. ACS nano 2013, 7, 9298.

(36) Battaglia, G.; Ryan, A. J.; Tomas, S. Langmuir 2006, 22, 4910.

(37) Lee, J. S.; Feijen, J. J. Control. Release 2012, 161, 473.

(38) Matoori, S.; Leroux, J. C. Materials Horizons 2020, 7, 1297.

(39) Lorenceau, E.; Utada, A. S.; Link, D. R.; Cristobal, G.; Joanicot, M.; Weitz, D. A. Langmuir 2005, 21, 9183 .

(40) Quan, L.; Ding, H. Y.; Pan, C. J.; Wei, Y. C.; Xie, Z. G. Colloids and Surfaces B-Biointerfaces 2018, 161, 156.

(41) Cevc, G.; M Allen, T.; S.L., N. In Phospholipids handbbok; New York, Basel: Marcel Dekker, Inc. ed.; Cevc, G., Ed.; Marcel Dekker Inc.: New York, 1993.

(42) Poschenrieder, S. T.; Klermund, L.; Langer, B.; Castiglione, K. Langmuir 2017, 33, 6011.

(43) Carlsen, A.; Glaser, N.; Le Meins, J.-F.; Lecommandoux, S. Langmuir 2011, 27, 4884.

(44) Itel, F.; Chami, M.; Najer, A.; Loercher, S.; Wu, D.; Dinu, I. A.; Meier, W. Macromolecules 2014, 47, 7588 . 
Large hybrid polymerllipid unilamellar vesicle (LHUV) at the nanoscale: An insight into the lipid distribution in the membrane and permeability control.

Martin Fauquignon ${ }^{1}$, Elise Courtecuisse ${ }^{1}$, Romane Josselin ${ }^{1}$, Angela Mutschler ${ }^{1}$ Annie Brûlet ${ }^{2}$, Marc

Schmutz ${ }^{3}$ and Jean-François Le Meins ${ }^{1, *}$

\section{SUPPORTING INFORMATION}

S1. Materials 1

S2. Methods 1

S2.1. Dynamic light scattering. 1

S2.2. Small angle neutron scattering 2

S.2.4. Fluorescein encapsulation and release 10

\section{S1. Materials}

POPC (1-palmitoyl-2-oleoyl-sn-glycero-3-phosphocholine), partially deuterated POPC-d31 (1palmitoyl d31-2-oleoyl-sn-glycero-3-phosphocholine) and DOPE-Rhod (1,2-dioleoyl-sn-glycero-3phosphoethanolamine- $\mathrm{N}$-(lissamine rhodamine B sulfonyl)) were obtained from Avanti Polar Lipids Inc. (Alabaster, Canada).

The different diblock copolymers PDMS- $b$-PEO and NBD-labelled PDMS chain were synthesized and characterized according to protocols described in a previous study. ${ }^{1}$

\section{S2. Methods}

\section{S2.1. Dynamic light scattering}

Hybrid vesicles were characterized by Dynamic Light Scattering (DLS) at $90^{\circ}$ using a Malvern Zetasizer Nano ZS90 at $20^{\circ} \mathrm{C}$. Results are listed in Table S1. A complete characterization of the pure polymersomes by static and dynamic light scattering is available in a previous study. ${ }^{1}$ 


\begin{tabular}{|c|c|c|c|c|}
\hline & $\begin{array}{l}\text { Time after } \\
\text { formation }\end{array}$ & $\begin{array}{c}\mathrm{D}_{\mathrm{h}} \\
(\mathrm{nm})\end{array}$ & PDI & $\begin{array}{c}\text { Scattered } \\
\text { intensity (a.u.) }\end{array}$ \\
\hline \multirow{2}{*}{ POPC } & $\mathrm{t}_{0}$ & 122 & 0,08 & 27189 \\
\hline & + 500 days & 337 & 0,30 & 1107 \\
\hline \multirow{2}{*}{$\begin{array}{c}\mathrm{Si}_{23} \mathrm{EO}_{13} \\
+\mathbf{1 5 \%} \mathrm{POPC}\end{array}$} & $\mathrm{t}_{0}$ & 97 & 0,09 & 20707 \\
\hline & + 500 days & 129 & 0,07 & 21416 \\
\hline \multirow{2}{*}{$\begin{array}{c}\mathrm{Si}_{23} \mathrm{EO}_{13} \\
+25 \% \mathrm{POPC}\end{array}$} & $\mathrm{t}_{0}$ & 120 & 0,05 & 11759 \\
\hline & + 500 days & 130 & 0,11 & 23775 \\
\hline \multirow{2}{*}{$\begin{aligned} & \mathrm{Si}_{27} \mathrm{EO}_{17} \\
+ & 15 \% \mathrm{POPC}\end{aligned}$} & $\mathrm{t}_{0}$ & 100 & 0,10 & 13250 \\
\hline & + 500 days & 113 & 0,06 & 12003 \\
\hline \multirow{2}{*}{$\begin{array}{c}\mathrm{Si}_{27} \mathbf{E O}_{17} \\
+25 \% \text { POPC }\end{array}$} & $\mathrm{t}_{0}$ & 130 & 0,06 & 12982 \\
\hline & + 500days & 136 & 0,08 & 27047 \\
\hline \multirow{2}{*}{$\begin{aligned} & \mathrm{Si}_{36} \mathrm{EO}_{23} \\
+ & 25 \% \text { POPC }\end{aligned}$} & $\mathrm{t}_{0}$ & 120 & 0,16 & 13704 \\
\hline & + 500 days & 160 & 0,12 & 22120 \\
\hline
\end{tabular}

Table S1: Hydrodynamic diameter (Dh) and polydispersity index (PDI) of hybrid vesicles after formation t0 and 500 days after formation.

\section{S2.2. Small angle neutron scattering}

SANS experiments were carried out on PACE and PAXY spectrometers at Laboratoire Léon Brillouin (CEA Saclay, France). Different configurations were used to reach a scattering vector range $q$ from 0.002 to $0.15 \AA^{-1}$.

Pure lipid or copolymer vesicles were prepared in $\mathrm{D}_{2} \mathrm{O}$ at a concentration of $10 \mathrm{mg} \cdot \mathrm{ml}^{-1}$. For the hybrid vesicles, the contrast variation technique already used in a previous study $y^{2,3}$ was performed. A specific solvent mixture can match the scattering length density (SLD) of each component and thus hide its scattering contribution. To have access to the polymer signal, vesicles were prepared in $\mathrm{D}_{2} \mathrm{O} / \mathrm{H}_{2} \mathrm{O}$, 49/51, vol: $\mathrm{vol}\left(\mathrm{SLD}=2.710^{10} \mathrm{~cm}^{-2}\right.$ ) (named polymer contrast condition) at a concentration in polymer

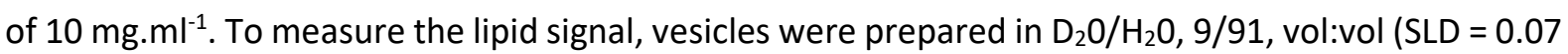
$10^{10} \mathrm{~cm}^{-2}$ ) (lipid contrast) at a concentration in lipid of $10 \mathrm{mg} \cdot \mathrm{ml}^{-1}$. Finally, to detect globally the polymer and POPC-d31, samples were prepared in pure $D_{2} \mathrm{O}\left(\mathrm{SLD}=6.3810^{10} \mathrm{~cm}^{-2}\right)$ (full contrast) at 10 $\mathrm{mg} \cdot \mathrm{ml}^{-1}$.

The samples were put in quartz $\mathrm{Hellma}^{\odot}$ cells with 1 or $2 \mathrm{~mm}$ path lengths and measured at room temperature.

The raw spectra were corrected from the empty cell and other sources by conventional procedures $\mathrm{s}^{4, \mathrm{i}}$ using LAMP program ${ }^{\mathrm{ii}}$ in order to obtain the SANS curves in absolute units $\left(\mathrm{cm}^{-1}\right)$. 
Different models have been used to analyse the scattering curves of the samples. Fits to the form factor of vesicle, disk or various core-shell cylinder were achieved using the SasView program ( http://www.sasview.org/). Another model of perforated vesicle developed in a previous study ${ }^{2}$ in order to describe the scattering of phase separated polymer/lipid vesicles was also used.

\section{Volume fraction parameter:}

Being aware that extrusion process can lead to a significant mass loss, all samples were quantified again, after the SANS experiments to verify the lipid and polymer volume fraction, which is an important parameter in the fitting procedure. The total polymer/lipid quantities were determined by thermogravimetry measurements. ${ }^{5}$ The theoretical volume fractions were determined as follows:

$$
\text { volume fraction theoretical }=C_{d r y}\left(\begin{array}{c}
\mathrm{f}_{\text {lipid }}\left(1-\mathrm{f}_{\text {hydr-lipid }}\right)+ \\
\mathrm{f}_{\text {polymer }}\left(1-\mathrm{f}_{\text {hydr-polymer }}\right)
\end{array}\right)
$$

$C_{\text {dry }}$ being the concentration determined after extrusion process via gravimetry, after drying a known volume of vesicle suspension. $f_{\text {lipid }}$ and $f_{\text {polymer }}$ are the mass fraction of lipid and polymer respectively, and $f_{\text {hydr-lipid, }} f_{\text {hydr-poly }}$ are the hydrophilic fraction in lipid and polymer respectively. The volume fractions obtained by fitting the SANS curves are in fair agreement with the theoretical volume fractions (Table S2, S4, S5).

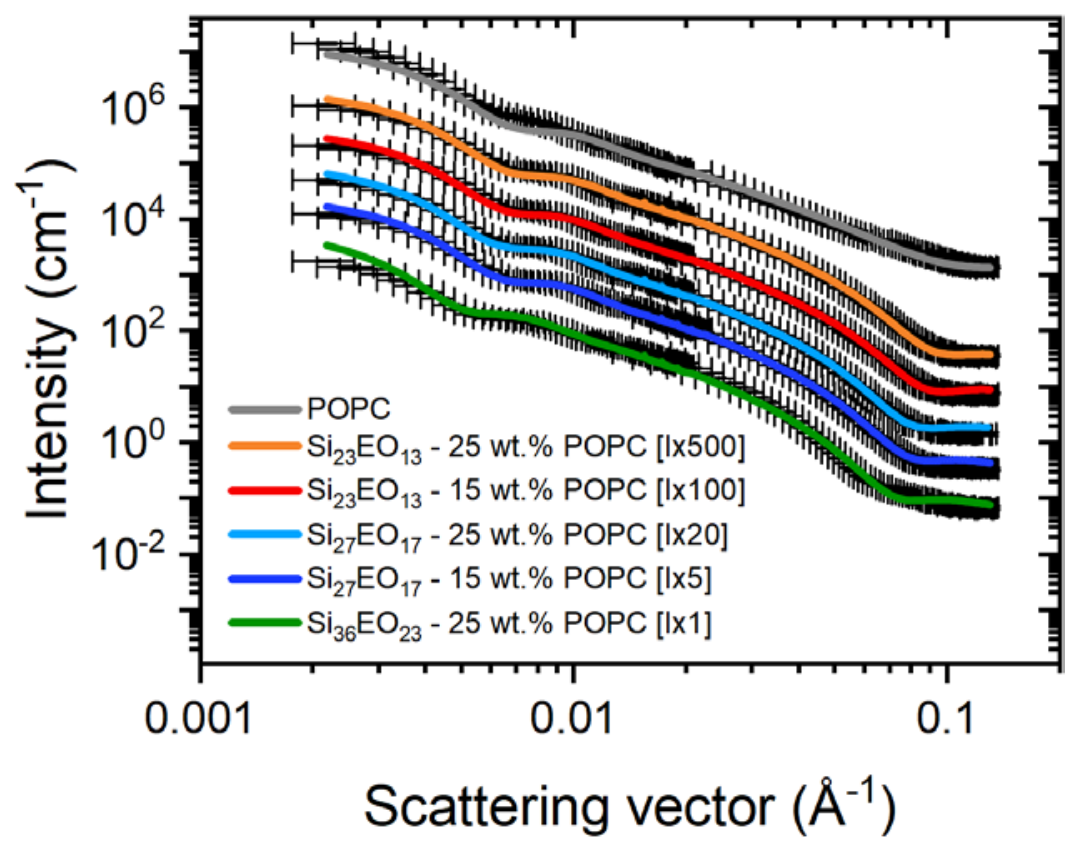

Figure S1: SANS curves obtained for the different samples in full contrast condition. Data are adjusted by the simple vesicle form factor (color lines). Curves have been shifted vertically for clarity (shift factors are indicated in the legend). 


\begin{tabular}{|c|c|c|c|c|c|c|}
\hline Copolymer & $\mathbf{S i}_{23} \mathbf{E} \mathbf{O}_{13}$ & $\mathbf{S i}_{23} \mathbf{E} \mathbf{O}_{13}$ & $\mathbf{S i}_{27} \mathbf{E O}_{17}$ & $\mathbf{S i}_{27} \mathbf{E O}_{17}$ & $\mathbf{S i}_{36} \mathbf{E O}_{23}$ & \\
\hline $\begin{array}{l}\text { POPC mass } \\
\text { fraction }\end{array}$ & $15 \%$ & $25 \%$ & $15 \%$ & $25 \%$ & $25 \%$ & РОРС \\
\hline $\begin{array}{l}\text { Background } \\
\left(\mathrm{cm}^{-1}\right)\end{array}$ & 0.068 & 0.057 & 0.068 & 0.068 & 0.065 & 0.065 \\
\hline $\begin{array}{c}\text { SLD } \\
\left(\times 10^{-6} \AA^{-2}\right)\end{array}$ & 0.471 & 0.745 & 0.471 & 0.745 & 0.745 & 2.800 \\
\hline $\begin{array}{l}\text { SLD solvent } \\
\left(\mathrm{x} 10^{-6} \AA^{-2}\right)\end{array}$ & 6.360 & 6.360 & 6.360 & 6.360 & 6.360 & 6.360 \\
\hline $\begin{array}{c}\text { Volume Fraction } \\
\text { (Fit) }\end{array}$ & 0.0060 & 0.0071 & 0.0062 & 0.0066 & 0.0053 & 0.0039 \\
\hline $\begin{array}{c}\text { Volume Fraction } \\
\text { (gravimetry) }\end{array}$ & 0.0055 & 0.0060 & 0.0053 & 0.0055 & 0.0046 & 0.0019 \\
\hline $\begin{array}{l}\text { Radius } \\
\text { (nm) }\end{array}$ & 39.8 & 38.7 & 40.2 & 41.5 & 51.2 & 38.5 \\
\hline $\begin{array}{c}\text { Radius dispersity } \\
\text { (log-normal } \\
\text { distribution) }\end{array}$ & 0.250 & 0.250 & 0.250 & 0.250 & 0.250 & 0.250 \\
\hline $\begin{array}{l}\text { Thickness } \\
\text { (nm) }\end{array}$ & 6.7 & 6.3 & 7.4 & 7.3 & 8.2 & 4.7 \\
\hline $\begin{array}{l}\text { Thickness } \\
\text { dispersity } \\
\text { (log-normal } \\
\text { distribution) }\end{array}$ & 0.106 & 0.146 & 0.145 & 0.132 & 0.145 & 0.150 \\
\hline
\end{tabular}

Table S2: Fit parameters to the vesicle form factor obtained for LHUVs in full contrast condition.

In lipid contrast condition, the vesicle form factor could also be used but different set of parameters fit similarly the data, as indicated in Table S3: 


\begin{tabular}{|c|c|c|c|}
\hline & Fit $n^{\circ} 1$ & Fit $n^{\circ} 2$ & Fit $n^{\circ} 3$ \\
\hline $\begin{array}{c}\text { Background } \\
\left(\mathrm{cm}^{-1}\right)\end{array}$ & \multicolumn{3}{|c|}{1.015} \\
\hline $\begin{array}{c}\text { SLD } \\
\left(\mathrm{x} 10^{-6} \AA^{-2}\right) *\end{array}$ & \multicolumn{3}{|c|}{2.800} \\
\hline $\begin{array}{l}\text { SLD solvent } \\
\left(\mathrm{x} 10^{-6} \AA^{-2}\right) *\end{array}$ & \multicolumn{3}{|c|}{0.060} \\
\hline Volume fraction & 0.0008 & 0.0009 & 0.0011 \\
\hline Radius (nm) & 39.3 & 38.3 & 39.8 \\
\hline $\begin{array}{c}\text { Radius dispersity } \\
\text { (log-normal distribution) }\end{array}$ & 0.250 & 0.250 & 0.250 \\
\hline Thickness (nm) & 9.6 & 7.7 & 6.3 \\
\hline $\begin{array}{c}\text { Thickness dispersity } \\
\text { (log-normal distribution) }\end{array}$ & 0.022 & 0.063 & 0.029 \\
\hline
\end{tabular}

Table S3: Illustration of the difficulty to fit data in lipid contrast condition with the vesicle form factor.

*: SLD fixed. Different sets of parameters could equally fit the data of $\mathrm{Si}_{27} \mathrm{EO}_{17} 25 \%$ POPC.

The membrane thickness obtained with vesicle form factor fit being relatively variable, we therefore used the approximation of large vesicle measured in the intermediate $q$ range for the vesicle radius and the Guinier range for the membrane thickness in order to obtain an average value of membrane thickness using Krakty-Porod representations shown in Figure S2. The slope of the linear fit in the intermediate q range equals $\frac{\delta^{2}}{12}$, where $\delta$ is the average membrane thickness. 


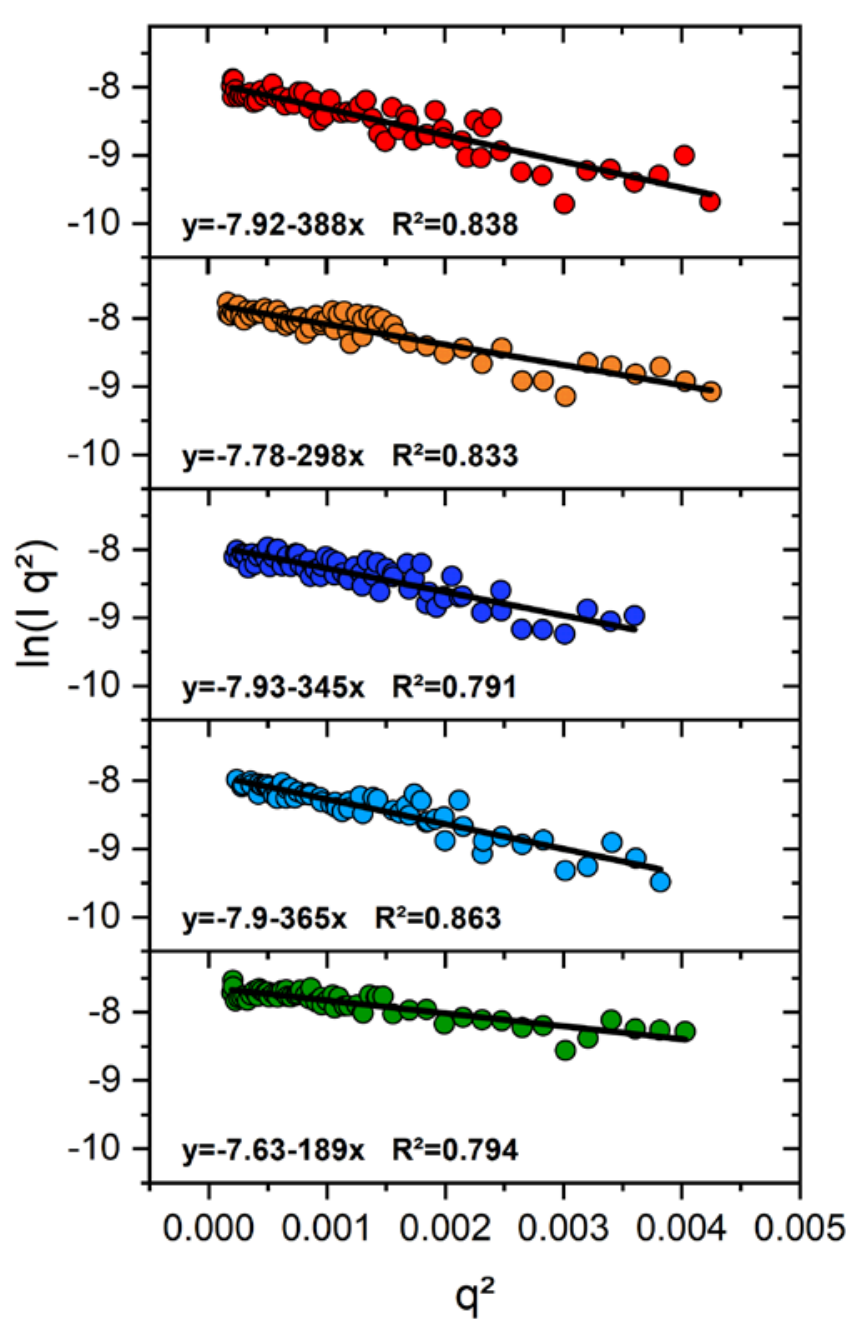

Figure S2: Kratky-Porod representation of the SANS data for different LHUV samples in lipid contrast condition; from top to bottom $\mathrm{Si}_{23} \mathrm{EO}_{13}+15 \%$ POPC (red), $\mathrm{Si}_{23} \mathrm{EO}_{13}+25 \%$ POPC (orange), $\mathrm{Si}_{27} \mathrm{EO}_{17}+$ $15 \%$ POPC (blue), $\mathrm{Si}_{27} \mathrm{EO}_{17}+25 \%$ POPC (light blue) et $\mathrm{Si}_{36} \mathrm{EO}_{23}+25 \%$ POPC (green). Data are fitted by linear regression (dotted line).The slope of the linear equation equals $\frac{\delta^{2}}{12}$, where $\delta$ is the average membrane thickness of LHUV. 


\begin{tabular}{|c|c|c|c|}
\hline & \multicolumn{3}{|c|}{$\mathbf{S i}_{36} \mathbf{E O}_{23}$} \\
\hline & \multicolumn{3}{|c|}{ 25\% POPC } \\
\hline & $\begin{array}{c}\text { Full } \\
\text { contrast }\end{array}$ & $\begin{array}{l}\text { Polymer } \\
\text { contrast }\end{array}$ & $\begin{array}{c}\text { Lipid } \\
\text { contrast }\end{array}$ \\
\hline $\begin{array}{l}\text { Background } \\
\left(\mathrm{cm}^{-1}\right)\end{array}$ & 0.065 & 0.705 & 1.017 \\
\hline $\begin{array}{c}\text { SLD } \\
\left(\times 10^{-6} \AA^{-2}\right)^{*}\end{array}$ & 0.745 & 0.060 & 2.800 \\
\hline $\begin{array}{l}\text { SLD solvent } \\
\left(\mathrm{x} 10^{-6} \AA^{-2}\right)^{*}\end{array}$ & 6.360 & 2.800 & 0.060 \\
\hline Volume fraction & 0.0053 & 0.0036 & 0.0019 \\
\hline Theoretical volumefraction ${ }^{a}$ & 0.0046 & 0.0052 & 0.0010 \\
\hline Radius (nm) & 51.2 & 44.3 & 41.6 \\
\hline $\begin{array}{c}\text { Radius dispersity } \\
\text { (lognormal distribution) }\end{array}$ & 0.250 & 0.250 & 0.250 \\
\hline Thickness (nm) & 8.2 & 7.9 & $4.8 * *$ \\
\hline $\begin{array}{l}\text { Thickness dispersity } \\
\text { (lognormal distribution) }\end{array}$ & 0.145 & 0.027 & 0.150 \\
\hline
\end{tabular}

Table S4: Parameters used to fit the data for $\mathrm{LHUV}$ of $\mathrm{Si}_{36} \mathrm{EO}_{23}$ with the vesicle form factor for different contrast conditions. ${ }^{\text {: }}$ Volume fraction calculated from Eq. S3 after gravimetry. *: SLD fixed. **: value deduced from the linear fit in the Kratky-Porod representation of SANS curve (Fig. S7) set fixed for the fit. 


\begin{tabular}{|c|c|c|c|c|c|c|}
\hline & \multicolumn{6}{|c|}{$\mathbf{S i}_{27} \mathbf{E O}_{17}$} \\
\hline & \multicolumn{3}{|c|}{ 15\% POPC } & \multicolumn{3}{|c|}{ 25\% POPC } \\
\hline & $\begin{array}{c}\text { Full } \\
\text { contrast }\end{array}$ & $\begin{array}{l}\text { Polymer } \\
\text { contrast }\end{array}$ & $\begin{array}{c}\text { Lipid } \\
\text { contrast }\end{array}$ & $\begin{array}{c}\text { Full } \\
\text { contrast }\end{array}$ & $\begin{array}{l}\text { Polymer } \\
\text { contrast }\end{array}$ & $\begin{array}{c}\text { Lipid } \\
\text { contrast }\end{array}$ \\
\hline $\begin{array}{c}\text { Background } \\
\left(\mathrm{cm}^{-1}\right)\end{array}$ & 0.068 & 0.665 & 1.025 & 0.068 & 0.667 & 1.015 \\
\hline $\begin{array}{c}\text { SLD } \\
\left(\times 10^{-6} \AA^{-2}\right)^{*}\end{array}$ & 0.471 & 0.060 & 2.800 & 0.745 & 0.060 & 2.800 \\
\hline $\begin{array}{l}\text { SLD solvent } \\
\left(\mathrm{x} 10^{-6} \AA^{-2}\right)^{*}\end{array}$ & 6.360 & 2.800 & 0.060 & 6.360 & 2.800 & 0.060 \\
\hline Volume fraction & 0.0062 & 0.0049 & 0.0012 & 0.0066 & 0.0052 & 0.0011 \\
\hline $\begin{array}{c}\text { Theoretical volume } \\
\text { fraction }^{\mathrm{a}}\end{array}$ & 0.0053 & 0.0058 & 0.0012 & 0.0055 & 0.0062 & 0.0010 \\
\hline Radius (nm) & 40.2 & 39.3 & 39.9 & 41.5 & 36.9 & 40.5 \\
\hline $\begin{array}{c}\text { Radius dispersity } \\
\text { (log-normal } \\
\text { distribution) }\end{array}$ & 0.250 & 0.250 & 0.250 & 0.250 & 0.250 & 0.250 \\
\hline Thickness (nm) & 7.4 & 7.5 & $6.4 * *$ & 7.3 & 7.1 & $6.6 * *$ \\
\hline $\begin{array}{l}\text { Thickness } \\
\text { dispersity } \\
\text { (log-normal } \\
\text { distribution) }\end{array}$ & 0.145 & 0.113 & 0.15 & 0.132 & 0.137 & 0.119 \\
\hline
\end{tabular}

Table S5: Parameters used to fit the data for $\mathrm{LHUV}$ of $\mathrm{Si}_{27} \mathrm{EO}_{17}$ with the vesicle form factor for different contrast conditions. ${ }^{\text {a: }}$ Volume fraction calculated from Eq. S3 ${ }^{*}$ : SLD fixed. ${ }^{* *}$ : value deduced from the linear fit in the Kratky-Porod representation of SANS curve (Fig. S7) set fixed for the fit. 


\begin{tabular}{|c|c|c|c|c|c|c|}
\hline & \multicolumn{6}{|c|}{$\mathbf{S i}_{23} \mathbf{E} \mathbf{O}_{13}$} \\
\hline & \multicolumn{3}{|c|}{ 15\% POPC } & \multicolumn{3}{|c|}{$25 \%$ POPC } \\
\hline & $\begin{array}{c}\text { Full } \\
\text { contrast }\end{array}$ & $\begin{array}{l}\text { Polymer } \\
\text { contrast }\end{array}$ & $\begin{array}{c}\text { Lipid } \\
\text { contrast }\end{array}$ & $\begin{array}{c}\text { Full } \\
\text { contrast }\end{array}$ & $\begin{array}{l}\text { Polymer } \\
\text { contrast }\end{array}$ & $\begin{array}{c}\text { Lipid } \\
\text { contrast }\end{array}$ \\
\hline $\begin{array}{l}\text { Background } \\
\left(\mathrm{cm}^{-1}\right)\end{array}$ & 0.068 & 0.675 & 1.019 & 0.057 & 0.675 & 1.021 \\
\hline $\begin{array}{c}\text { SLD } \\
\left(\mathrm{x} 10^{-6} \AA^{-2}\right)^{*}\end{array}$ & 0.471 & 0.060 & 2.800 & 0.745 & 0.060 & 2.800 \\
\hline $\begin{array}{l}\text { SLD solvent } \\
\left(\mathrm{x} 10^{-6} \AA^{-2}\right)^{*}\end{array}$ & 6.360 & 2.800 & 0.060 & 6.360 & 2.800 & 0.060 \\
\hline Volume fraction & 0.0060 & 0.0051 & 0.0011 & 0.0071 & 0.0052 & 0.0013 \\
\hline $\begin{array}{c}\text { Theoretical volume } \\
\text { fraction }^{\mathrm{a}}\end{array}$ & 0.0055 & 0.0068 & 0.0013 & 0.0060 & 0.0069 & 0.0013 \\
\hline Radius (nm) & 39.8 & 38.2 & 35.9 & 38.7 & 37.6 & 39.4 \\
\hline $\begin{array}{c}\text { Radius dispersity } \\
\text { (log-normal } \\
\text { distribution) } \\
\end{array}$ & 0.250 & 0.250 & 0.250 & 0.250 & 0.250 & 0.231 \\
\hline Thickness (nm) & 6.7 & 6.4 & $6.8 * *$ & 6.3 & 6.2 & $6.0 * *$ \\
\hline $\begin{array}{l}\text { Thickness } \\
\text { dispersity } \\
\text { (log-normal } \\
\text { distribution) } \\
\end{array}$ & 0.106 & 0.084 & 0.091 & 0.146 & 0.124 & 0.150 \\
\hline
\end{tabular}

Table S1: Parameters used to fit the data for LHUV of $\mathrm{Si}_{23} \mathrm{EO}_{13}$ with the vesicle form factor for different conditions. ${ }^{\text {a: }}$ Volume fraction calculated from Eq. S3. *: SLD fixed. ${ }^{* *}$ : value deduced from the linear fit in the Kratky-Porod representation of SANS (Fig. S7) set fixed for the fit. 


\section{S.2.4. Fluorescein encapsulation and release}

The quantification of the permeability has been made through measurement of UV absorbance of fluorescein released through the vesicle membrane. A calibration curve has been first performed with fluorescein in PBS 1X (Figure S3).

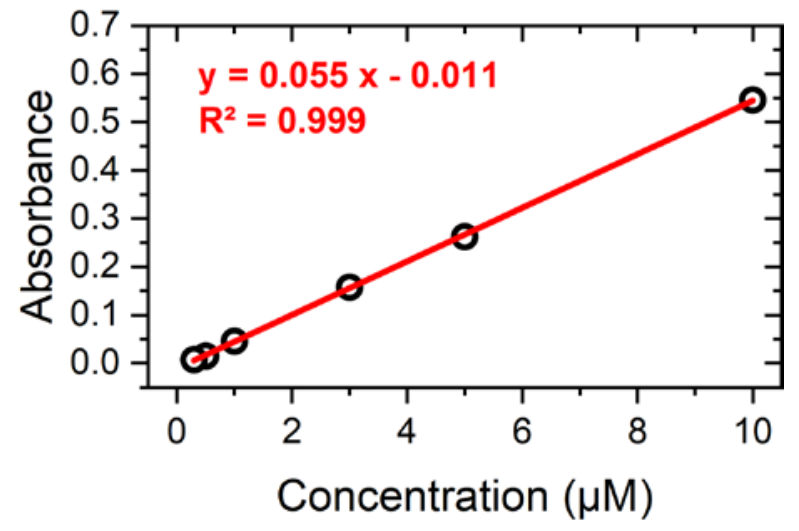

Figure S3: Calibration curve of UV absorbance of fluorescein in phosphate buffer saline (PBS) $1 \mathrm{X}$ at $25^{\circ} \mathrm{C}$.

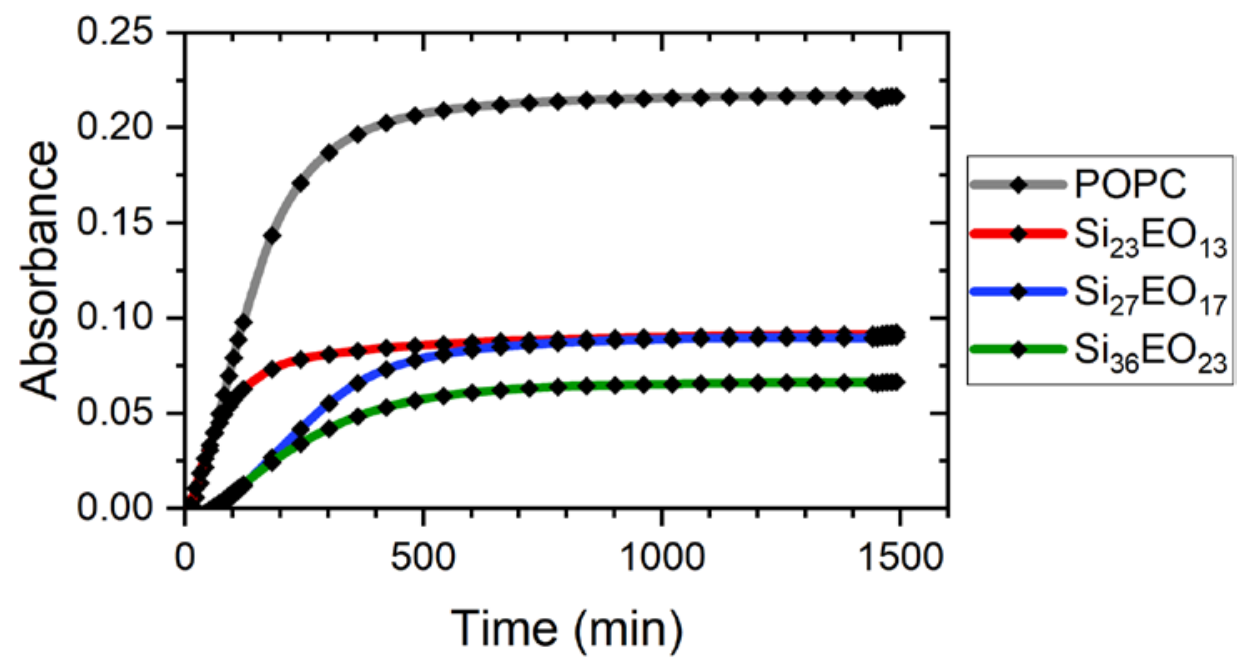

Figure S4: Evolution of UV absorbance due to fluorescein release from pure liposomes and polymersomes. 


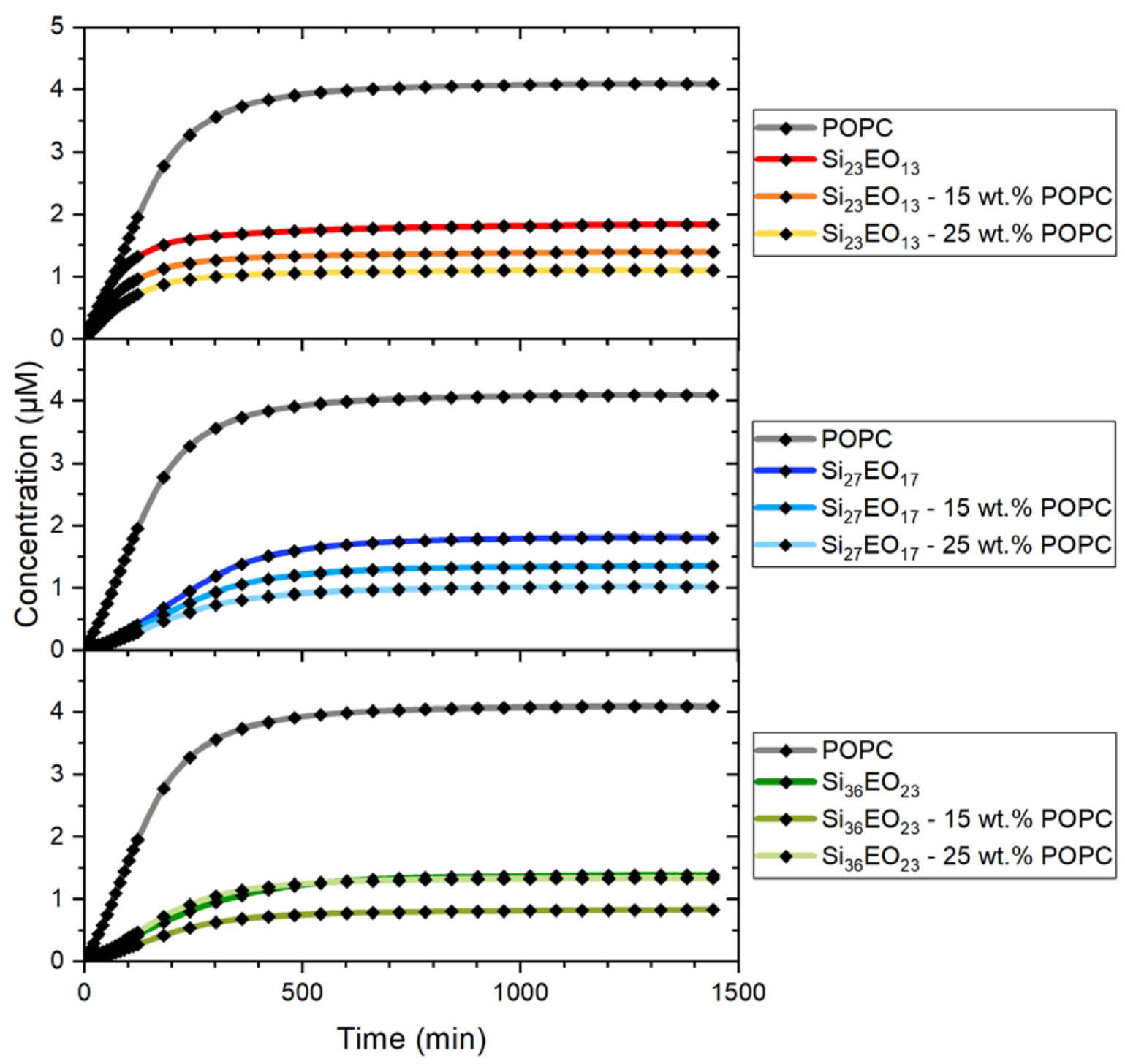

Figure S5: Evolution of the concentration of fluorescein during release experiments for pure liposomes, pure polymersomes and hybrid vesicles.

REFERENCES

(1) Fauquignon, M.; Ibarboure, E.; Carlotti, S.; Brûlet, A.; Schmutz, M.; Le Meins, J.-F. Polymers 2019, 11, 2013.

(2) Dao, T. P. T.; Brûlet, A.; Fernandes, F.; Er-Rafik, M.; Ferji, K.; Schweins, R.; Chapel, J. P.; Fedorov, A.; Schmutz, M.; Prieto, M.; Sandre, O.; Le Meins, J. F. Langmuir 2017, 33, 1705.

(3) Dao, T. P. T.; Fernandes, F.; Er-Rafik, M.; Salva, R.; Schmutz, M.; Brulet, A.; Prieto, M.; Sandre, O.; Le Meins, J. F. ACS Macro Letters 2015, 4, 182.

(4) Cotton, J. P. Neutron, X-Ray and Light Scattering; Elsevier: North-Holland, 1991; Vol. p.19.

(5) McClare, C. Anal. Biochem 1971, 39. 
'Brûlet, A.; Lairez, D.; Lapp, A. and Cotton, J.P. J. Appl. Cryst. 2007, 40, 165-177.

ii LAMP, the Large Array Manipulation Program. http://www.ill.eu/data_treat/lamp/the-lamp-book/ 